\title{
The Consistent Behavior of Tropical Rain: Average Reflectivity Vertical Profiles Determined by Rain Top Height $\mathscr{O}$
}

\author{
Reuven H. Heiblum, Ilan Koren, AND Orit Altaratz \\ Department of Earth and Planetary Sciences, Weizmann Institute of Science, Rehovot, Israel \\ AleXANDER B. Kostinski \\ Department of Physics, Michigan Technological University, Houghton, Michigan
}

(Manuscript received 28 March 2016, in final form 19 October 2016)

\begin{abstract}
Sixteen years of Tropical Rain Measuring Mission (TRMM) reflectivity profile data are collected for oceanic, continental, and island tropical regions within the boreal winter intertropical convergence zone (ITCZ). When sorted by the rain top height (RTH), a consistent behavior emerges where the average reflectivity profiles originating at different RTHs form non-overlapping manifolds in the height-reflectivity space, excluding the brightband regions for stratiform type profiles. Based on reflectivity slope $\left(\mathrm{dBZ} \mathrm{km}^{-1}\right)$ profile characteristics and physical considerations, the profiles are divided into three classes: 1) cold profiles, which originate above the $-20^{\circ} \mathrm{C}$ isotherm height and display convergence to a single reflectivity slope profile independent of RTH; 2) warm profiles, which originate below the $0^{\circ} \mathrm{C}$ isotherm height and display strong reflectivity slope dependence on RTH, with slope values per RTH linearly decreasing with decreased height; and 3) mixed profiles, which originate at the layer located in between the lowest cold rain and highest warm rain profiles and show a gradual transition from cold profile to warm profile reflectivity slope behavior. Stratiform type profiles show similarity for all regions. It is shown that the typical tropical stratiform cold rain profile can be simply parameterized given the temperature profile. Convective type profiles present larger interregional differences. Their deviation from the typical stratiform cold rain profile is used as a measure for convective intensity, where continental and island regions show larger deviations compared to oceanic ones.
\end{abstract}

\section{Introduction}

Rain plays an important component in both the energy budget and hydrological cycle of Earth (Held and Soden 2006; Marvel and Bonfils 2013; Trenberth et al. 2009). With respect to the energy cycle and distribution of heat, air laden with moisture in tropical regions [especially the intertropical convergence zone (ITCZ)] ascends to the high troposphere, where latent heat is released and transported poleward, fueling the global circulation. The importance with respect to the hydrological cycle is straightforward, as rainfall is the main natural source of freshwater over land. Hence, understanding

Supplemental information related to this paper is available at the Journals Online website: http://dx.doi.org/10.1175/ JHM-D-16-0078.s1.

Corresponding author e-mail: Ilan Koren, ilan.koren@weizmann. ac.il rain is crucial when dealing with global circulation and hydrological models, especially in light of predicted global warming scenarios, which are expected to alter rain patterns and distributions as well as global temperatures (Coumou and Rahmstorf 2012; Held and Soden 2006; Marvel and Bonfils 2013).

The Tropical Rainfall Measuring Mission (TRMM), lasting from late 1997 to early 2015, was designed to collect rainfall data over tropical and subtropical regions. Equipped with a first-of-its-kind spaceborne Precipitation Radar (PR; Kozu et al. 1994), TRMM retrieved explicit measurements of backscattered radiation from precipitation hydrometeors to obtain reflectivity vertical profiles. Measurements from the PR are often used as validation for the IR and microwave passive sensor measurements (Petty and Li 2013; Viltard et al. 2006). Although TRMM data only include instantaneous snapshots of rain events, by collecting large statistics from many overpasses, one can span the whole range of profile types and temporal stages of profile 
evolution for a given region. These data can then be used to link vertical profile characteristics with physical mechanisms of hydrometeor growth, phase change, etc. Many studies using ground-based radars or TRMM PR data focused primarily on surface rainfall and comparisons with ground-based rain gauges as part of ground validation (e.g., Bolen and Chandrasekar 2000; Kirstetter et al. 2013b; Liao and Meneghini 2009; Wang and Wolff 2012). Here, we use the vast statistics from TRMM PR to try and understand the structures of average reflectivity profiles within the ITCZ.

Assuming Rayleigh approximation, reflectivity $Z\left(\mathrm{~mm}^{6} \mathrm{~m}^{-3}\right)$ is shown to be proportional to the sixth moment of the precipitation hydrometeor size distribution, that is, $Z \propto D^{6}$ (Wilson and Brandes 1979). We note that the Rayleigh approximation can be considered valid using the TRMM PR (Arai and Liang 2010; Gunn and East 1954) for all but the highest rain rates (i.e., larger than $\sim 20 \mathrm{~mm} \mathrm{~h}^{-1}$ ) that are relatively uncommon. Although reflectivity is an indirect measure for the precipitation hydrometeor size distributions (PSDs), it is highly sensitive to the larger hydrometeor sizes and can be used as a proxy for hydrometeor growth processes in clouds. In general, reflectivity profiles are shown to increase with decreasing height (Kirstetter et al. 2013a; Konrad 1978; Liu 2003). This is also seen in section 3 a below, where most average reflectivity profiles tend to increase with decreasing heights. Taking the exponential distribution (a special case of the more general gamma parameterization; Uijlenhoet et al. 2003) as a simplified representation for the PSD, the increase in reflectivity may be due to an increase in hydrometeor number, mean size, or both (see the appendix for details, neglecting other nonPSD-related effects like radar physical and geometrical properties or hydrometeor phase transitions that will be described below).

As a simple representation for hydrometeor growth in an average precipitation profile, it is useful to use the continuous collection (CC) framework (Bowen 1950; Ludlam 1951). Neglecting updrafts, one obtains the following expression for the diameter of an average hydrometeor falling within a population of liquid or ice cloud particles (taking the melted equivalent diameter for ice):

$$
\bar{D}=10^{6} \frac{E L}{2 \rho_{w}} H,
$$

where $E$ is the collection efficiency (dependent on sizes and phases of interacting water species), $\rho_{w}$ is the liquid or ice water density $\left(\mathrm{g} \mathrm{m}^{-3}\right), L$ is the cloud liquid/ice water content [CWC $\left(\mathrm{g} \mathrm{m}^{-3}\right)$ ], and $H(\mathrm{~km})$ is the distance traveled by the falling hydrometeor.
We note that for individual profiles continuous collection is most applicable in the case of stratiform rain, where weak vertical motions are present. In growing stages of convective cells, significant updrafts may either increase the expected falling hydrometeor size with distance traveled due to increased time of growth or even reverse the direction of hydrometeor growth (i.e., size increase with increasing height; more details below). Moreover, in reality hydrometeor growth is of stochastic nature and that continuous collection typically underestimates hydrometeor growth (Berry 1967; Young 1975). It is necessary to incorporate processes such as incloud turbulence (Kostinski and Shaw 2005; Xue et al. 2008), droplet breakup (List et al. 1987; Seifert et al. 2005), and specific storm dynamics (Snyder et al. 2015) to capture the evolution of individual reflectivity profiles.

Nevertheless, the average profiles demonstrate that Eq. (1) may be a valid approximation in many cases and that hydrometeor size should scale with height. Equation (1) also illustrates the fact that growth processes depend on the particle size distribution, temperature, and CWC (sum of liquid and ice water contents). The latter two determine the type of hydrometeor expected to form (Kobayashi 1961; Korolev et al. 2003; Mossop and Hallett 1974) and therefore the expected types of interactions between water species (e.g., aggregation, riming, and collision-coalescence; Ludlam 1952; Pruppacher and Klett 1978; Rosenfeld and Lensky 1998). In addition, the temperature profile determines the hydrometeors' phase, which influences the measured effective reflectivity via the dielectric constant (Probert-Jones 1962; Uijlenhoet 2001; see section 2c for more details).

Several previous studies have attempted to establish statistical models for reflectivity profiles from groundbased radars, focusing mostly on profiles with tops located above the melting level (cold rain, including ice phase). For simplicity, we shall hereafter refer to reflectivity in logarithmic units (dBZ; see section $2 b)$ and consider increases in reflectivity with distance traveled from a reference top height as positive reflectivity slope. Konrad (1978) has shown that above the melting level, cloud core reflectivity profiles increase

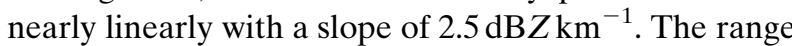
of reflectivity slopes around the cloud core reflectivity peak from observations was shown to be between 1.5 and $3 \mathrm{dBZ} \mathrm{km}{ }^{-1}$. Others have reported convective $\mathrm{dB} Z$ slopes above the melting level (from $\sim 0^{\circ}$ to $-20^{\circ} \mathrm{C}$ temperature range) ranging from 1.3 to $6.5 \mathrm{dBZ} \mathrm{\textrm {km } ^ { - 1 }}$ (Yuter and Houze 1995; Zipser and Lutz 1994), with $\sim 1.5 \mathrm{dBZ} \mathrm{km}^{-1}$ applying to continental intense storms, $\sim 4 \mathrm{dBZ} \mathrm{km}^{-1}$ applying to continental showers, and 


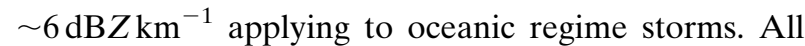
studies have found the reflectivity slope slightly above the melting level to decrease as peak profile reflectivity increases (e.g., the most intense continental hail storms exhibit lowest $\mathrm{dB} Z$ slopes).

The reflectivity slopes below the melting level for profiles with tops colder than $0^{\circ} \mathrm{C}$ were found to remain nearly constant till the surface (Harper 1957; Konrad 1978; Zipser and Lutz 1994). Contrary to these findings, Liu and Zipser (2013) found that average reflectivity slopes below the melting level tend to be either positive (reflectivity increases toward the surface) over water or negative (reflectivity decreases toward the surface) over land. These findings are in agreement with previous studies (Donaldson 1961; Hirose and Nakamura 2004; Szoke et al. 1986) showing more negative reflectivity slopes nearby and below the melting layer for increased storm intensity. The negative slopes over land/increased convection areas can be explained with two main factors:

1) Land areas experience stronger convection with updrafts larger than the typical terminal velocity of many of the raindrops $\left(\sim 5 \mathrm{~m} \mathrm{~s}^{-1}\right)$. The raindrops elevate while still collecting cloud droplets that are carried with the updrafts, creating a negative reflectivity slope that typically peaks around the melting level (Liu and Zipser 2013; Yuter and Houze 1995).

2) Lower relative humidity below the cloud base over dry continental areas (mainly the African Sahel, southwestern United States, and Australia) results in subcloud evaporation of rain (Liu and Zipser 2013; Schumacher and Houze 2006).

The goal in this work is to use large statistics of the TRMM PR data to understand the nature of average reflectivity profiles within the tropical ITCZ. Previous studies have also used radar reflectivity statistics for complete vertical profile analyses (e.g., Konrad 1978; Liu 2003; Shige et al. 2004, 2013). However, contrary to the common procedure in the studies listed above of binning the data according to the surface reflectivity, here we follow another common approach (e.g., Furuzawa and Nakamura 2005; Takayabu 2002) and stratify the data according to the rain top height (RTH; see details in section $2 b$ ), revealing several characteristic behaviors of the reflectivity profiles that depend on their top height. Moreover, coupled with temperature profiles, we wish to link temperature-dependent microphysical processes with the "typical" vertical profile of reflectivity. Ultimately, one can use these findings to translate cloudtop heights to entire reflectivity profiles based only on a few physical assumptions. Such understanding of rain profiles can be of benefit to global circulation models where cloud and precipitation processes are parameterized (e.g., Donner et al. 2011; Liu et al. 2007).

\section{Methods}

\section{a. Datasets and regions of interest}

This work is based on data from the years 1997 to 2014, but is limited to the boreal winter (DJF) months, during which the location of the ITCZ belt is relatively stationary (Waliser and Gautier 1993). We note that analyses from within the ITCZ during other seasons are expected to yield similar results. In Fig. 1a, mean DJF surface rain rates $\left(\mathrm{mm} \mathrm{h}^{-1}\right)$ are shown between $35^{\circ} \mathrm{S}$ and $35^{\circ} \mathrm{N}$. The rain-rate data are based on TRMM 3B 43 , version 7, monthly rain-rate product [see Huffman and Bolvin (2014) for details]. The ITCZ belt is clearly highlighted, indicated by a zonal band of relatively high rain rates, located slightly above the equator over the oceans and slightly below the equator over continents. We selected twelve $5^{\circ} \times 5^{\circ}$ boxes residing within the ITCZ (see Fig. 1a), including four oceanic regions (midPacific, Atlantic, Indian Ocean, and Warm Pool), four continental regions (Amazon-West, Amazon-East, Africa-West, and Africa-East), and four island regions (Madagascar, Java-Sumatra, Borneo, and New Guinea). In Table 1 regional statistics of topography (see also contours in Fig. 1a) are displayed, showing considerable variance, ranging from shallow plains to extreme mountainous islands.

Meteorological data used for interregional comparison in this work were taken from GDAS reanalysis data (Parrish and Derber 1992; Saha et al. 2006). The data are of $1^{\circ}$ spatial resolution and 6-h temporal resolution. Only data within $3 \mathrm{~h}$ of a TRMM-measured rain event were taken into account. For each event, a $5^{\circ} \times 5^{\circ}$ regional average of chosen meteorological parameters (e.g., CAPE, precipitable water, temperature, and relative humidity vertical profiles) was taken. All events were then averaged together to get a mean value and corresponding standard deviation. Lifting condensation level (LCL) calculations were based on actual surface pressure, temperature, and relative humidity data (Bolton 1980).

Vertical profiles of reflectivity were obtained from the TRMM 2A25, version 7, product (Iguchi et al. 2000, 2009). The reflectivity obtained by TRMM is in fact effective reflectivity, where the dielectric constant of hydrometeors is assumed to be that of water for all heights. At nadir, TRMM PR has a footprint size of $\sim 5 \mathrm{~km}$ (was $\sim 4.3 \mathrm{~km}$ before 2001 orbit boost) and a vertical resolution of $250 \mathrm{~m}$ (Kozu et al. 1994; X.-T. Liu et al. 2012), reaching from the surface to $20 \mathrm{~km}$ above the geoid. The PR has an operation frequency of $13.8 \mathrm{GHz}(\sim 2.17-\mathrm{cm}$ wavelength $)$ and a sensitivity limit 

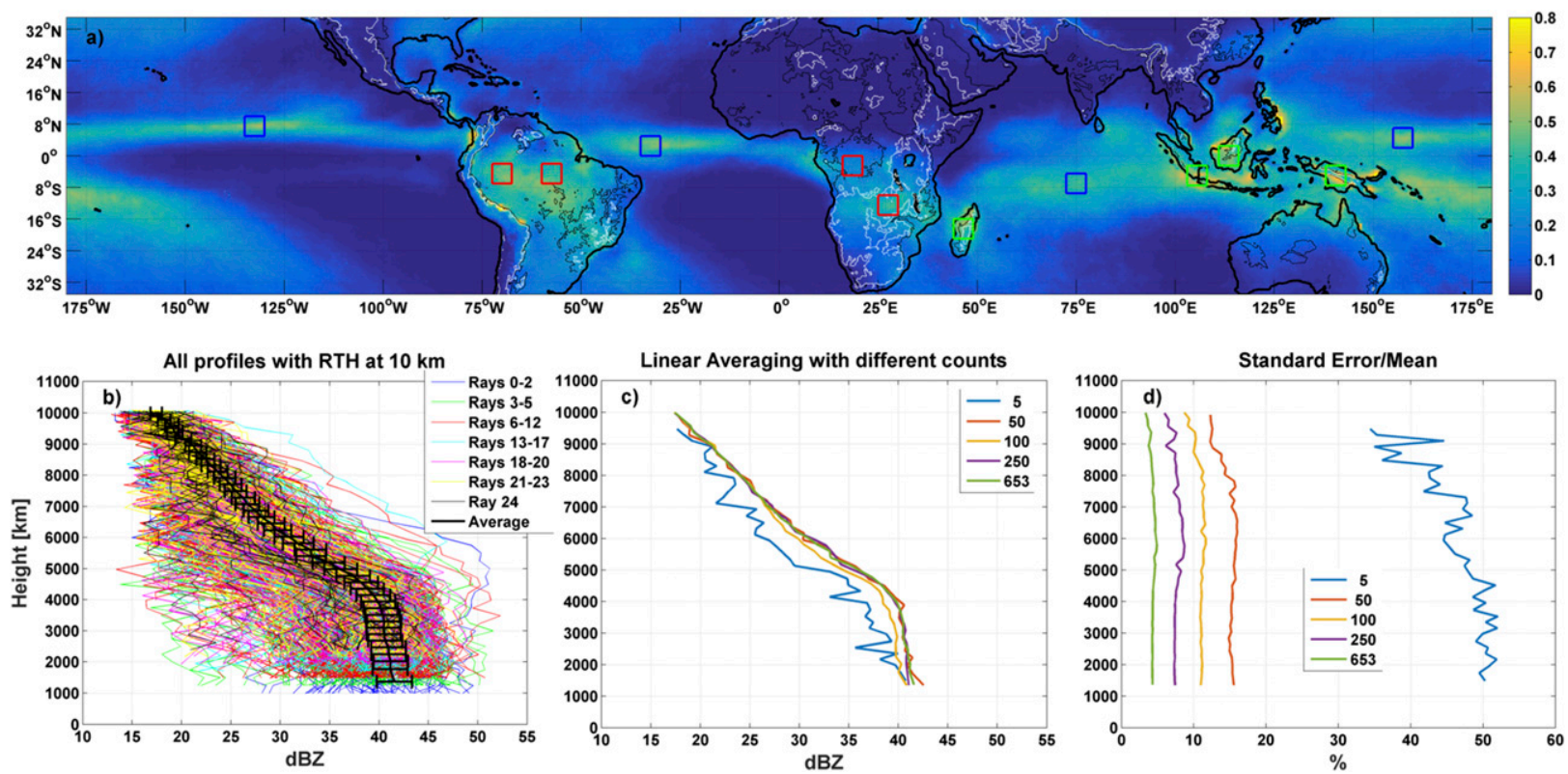

FIG. 1. (a) Twelve selected regions of interest, including four oceanic (blue boxes), four continental (red boxes), and four large islands (green boxes). All regions are $5^{\circ} \times 5^{\circ}$, named (from west to east): mid-Pacific $\left(5^{\circ}-10^{\circ} \mathrm{N}, 135^{\circ}-130^{\circ} \mathrm{W}\right)$, Amazon-West $\left(7^{\circ}-2^{\circ} \mathrm{S}, 72.5^{\circ}-\right.$ $\left.67.5^{\circ} \mathrm{W}\right)$, Amazon-East $\left(7^{\circ}-2^{\circ} \mathrm{S}, 60^{\circ}-55^{\circ} \mathrm{W}\right)$, Atlantic $\left(0^{\circ}-5^{\circ} \mathrm{N}, 35^{\circ}-30^{\circ} \mathrm{W}\right)$, Africa-West $\left(5^{\circ} \mathrm{S}-0^{\circ}, 16^{\circ}-21^{\circ} \mathrm{E}\right)$, Africa-East $\left(15^{\circ}-10^{\circ} \mathrm{S}, 25^{\circ}-\right.$ $\left.30^{\circ} \mathrm{E}\right)$, Madagascar $\left(21^{\circ}-16^{\circ} \mathrm{S}, 44^{\circ}-49^{\circ} \mathrm{E}\right)$, Indian Ocean $\left(9.5^{\circ}-4.5^{\circ} \mathrm{S}, 72.5^{\circ}-77.5^{\circ} \mathrm{E}\right)$, Java-Sumatra $\left(7.5^{\circ}-2.5^{\circ} \mathrm{S}, 103^{\circ}-108^{\circ} \mathrm{E}\right)$, Borneo $\left(2.5^{\circ} \mathrm{S}-2.5^{\circ} \mathrm{N}, 111^{\circ}-116^{\circ} \mathrm{E}\right)$, New Guinea $\left(7.5^{\circ}-2.5^{\circ} \mathrm{S}, 138^{\circ}-143^{\circ} \mathrm{E}\right)$, and Warm Pool $\left(2^{\circ}-7^{\circ} \mathrm{N}, 155^{\circ}-160^{\circ} \mathrm{E}\right)$. Background color scheme represents mean DJF rain rates $\left(\mathrm{mm} \mathrm{h}^{-1}\right)$ derived from the TRMM 3B43 product. Black and white inland contours mark the 0.5- and 1-km elevation heights, respectively. (b) All Atlantic region convective type (see section 2c) vertical profiles of reflectivity with RTH at $10 \pm 0.125 \mathrm{~km}$. Different line colors correspond to different instrument incidence angles, as indicated in legend. Boldface black line with error bars corresponds to the average reflectivity (using linear averaging, see section 2b) and standard error of the mean per height. (c) Average reflectivity profile using different number of individual profile samples (see legend for numbers). (d) Dependence of average profile standard error to mean value ratio on number of profile samples.

of $\sim 17 \mathrm{~dB} Z$ (Kummerow et al. 1998). The radar signal is subject to considerable path attenuation by hydrometeors, which is corrected for using a hybrid between the surface reference technique (SRT) and the HitschfeldBordan method (Meneghini et al. 2004). The attenuation correction together with nonuniform beam filling (especially for isolated convective elements) and significant clutter near the surface are considered as sources of errors in the PR data (Iguchi et al. 2009). As seen in section $2 \mathrm{~b}$, we attempt to limit surface clutter contamination that can affect the lower portions of vertical profiles up to heights of $\sim 2.5 \mathrm{~km}$ above the actual surface (Hirose et al. 2012). The other uncertainties are considered as inherent to the instrument/product algorithm and are not dealt with during this work.

\section{b. Data analysis and averaging}

The total amount of profile samples collected per region is shown in Table 1 , ranging from $6 \times 10^{5}$ for Africa-West to $1.3 \times 10^{6}$ for New Guinea. Data were constrained to include only nonintermittent profiles (i.e., profiles with no empty reflectivity measurements from profile top to bottom) that experienced certain surface rain (TRMM 2A25 estimated surface rain product $>0$ ), resulting in a reduction of $24 \%-32 \%$ in profile number per region. The nonintermittent constraint accounts for $\sim 15 \%-20 \%$ of the reduction, while the nonzero estimated surface rain constraint accounts for the rest. These constraints were applied to focus this analysis on mature- and dissipation-stage rain profiles without initial stages of the rain profile evolution where rain has yet to reach the surface. Moreover, the nonintermittent constraint removes highly variable reflectivity profiles (which add significant noise to the averaging) and limits the chance of rain clouds originating from different heights overlapping in a single TRMM pixel (e.g., large anvil above shallow cloud). However, because of the footprint size of $\sim 5 \mathrm{~km}$, we cannot exclude cases of coexisting rain clouds or rain types (i.e., convective and stratiform, see section 2c) within the same pixel.

As an example of the analysis procedure, all Atlanticregion convective profiles (a total of 653 profiles) originating from an RTH (i.e., the highest nonzero measurement in the profile, taking incidence angle into consideration to calculate true height above the geoid) of $10 \mathrm{~km}$ are shown 


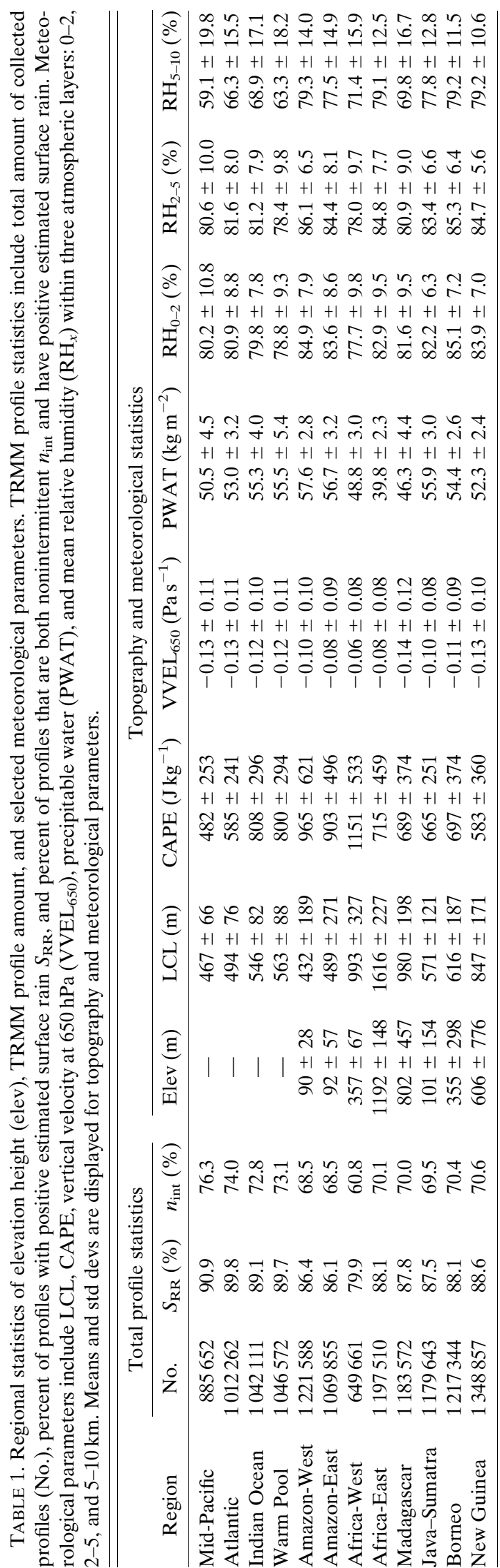

in Fig. 1b. Based on previous work (Hirose et al. 2012) and collected statistics of lowest clutter-free bins, we applied a conservative approach and discarded the lower portions of profiles at risk of surface clutter contamination. The thin lines of different color represent profiles of different incidence angles, from nadir (ray 0 ) to $\pm 17^{\circ}$ (ray 24). It can be seen that the lowest clutter-free height (above the actual topographic surface) taken in this work ranges from $1 \mathrm{~km}$ at nadir to $2.5 \mathrm{~km}$ at the slant edge. A large variation between individual profiles is seen, corresponding to different types or temporal stages within the lifetime of a convective core. However, is it noticeable that the density of profiles in the height versus $\mathrm{dB} Z$ space is not homogeneous and tends to peak near the average reflectivity profile (boldface black line, Fig. 1b) but at slightly lower reflectivity values, since the averaging was performed over linear reflectivity values that are positively skewed and thus biased to higher reflectivity.

In creating an average vertical profile, we followed the approach taken in previous studies (Heymsfield et al. 2000; Kitchen 1997; Rakovec 1997; Wang and Wolff 2009) and first converted logarithmic reflectivity (dBZ; unitless) to linear reflectivity (i.e., $Z ; \mathrm{mm}^{6} \mathrm{~m}^{-3}$ ) using the equation $Z=10^{\mathrm{dB} Z / 10}$ and then converted the average profile back to $\mathrm{dB} Z$ using the inverse relation. The averaging itself was performed by sorting profile data according to height so that each height bin had an equal amount of samples. This method limits the influence of low count statistics at either high or low altitudes. In addition, we applied a minimum threshold of 250 individual profiles for creating each average profile data point. This choice of threshold is justified in Figs. 1c and $1 d$, where we show the effect of changing the number of profile samples on the average reflectivity profile (Fig. 1c) and its corresponding standard error to mean value ratio, per height (Fig. 1d). It can be seen that even above 50 samples, the average profile nearly converges to that using hundreds of samples. However, to limit the ratio of standard error to mean value below $10 \%$, a sample size of at least 250 profiles is needed. Similar results are also seen for subsets of profiles from other RTHs.

\section{c. Rain classification}

We use TRMM 2A23 product classification of rain type to convective and stratiform types. The "others" rain type given by the product amounts to no more than $0.1 \%$ of the data (see Table 3 , described in greater detail below) and was excluded from this work. Rain type is defined as stratiform based on two main conditions (Awaka et al. 2009, 1997): 1) a brightband (BB) layer is measured in the vicinity of the melting level or 2) the 
TABLE 2. Temperature level boundaries $\left({ }^{\circ} \mathrm{C}\right)$ for cold, mixed, and warm rain subtypes and divided into stratiform and convective rain types. Convective rain types are further divided into ocean and land (i.e., continental and island) regions. Boundaries were derived using analyses as seen in Figs. 5 and 6. Note that the boundaries for stratiform rain are identical for both ocean and land.

\begin{tabular}{llll}
\hline \hline & \multicolumn{2}{c}{ Convective } \\
\cline { 3 - 4 } & Stratiform & \multicolumn{1}{c}{ Ocean } & \multicolumn{1}{c}{ Land } \\
\hline Cold & $T<-5^{\circ}$ & $T<-20^{\circ}$ & $T<-40^{\circ}$ \\
Mixed & $-5^{\circ}<T<5^{\circ}$ & $-20^{\circ}<T<0^{\circ}$ & $-40^{\circ}<T<0^{\circ}$ \\
Warm & $T>5^{\circ}$ & $T>0^{\circ}$ & $T>0^{\circ}$ \\
\hline
\end{tabular}

rain pixel is part of a cluster of pixels that experience spatially homogeneous reflectivity values or low reflectivity values. Convective rain type is generally assigned to the rest of the profiles. We note that for nonisolated warm (shallow) rain that is absent of the BB feature, stratiform profiles differ from convective ones solely by their reflectivity values. Finally, all profiles that are spatially isolated or contain extreme reflectivity measurements $(>39 \mathrm{dBZ})$ are classified as convective.

The BB feature appears as a reflectivity peak slightly below the altitude of the $0^{\circ} \mathrm{C}$ isotherm, in the melting layer of rain profiles. As ice phase hydrometeors descend below the $0^{\circ} \mathrm{C}$ level, they start to melt and obtain a liquid coating. Since the dielectric constant of water is higher than that of ice, there is a rapid increase in radar reflectivity, creating the BB peak. Moreover, increased aggregation (i.e., wet snow is "stickier"; Hosler et al. 1957; Mitchell 1988) and a density effect where frozen hydrometeors with a liquid coating appear like large rain drops (Fabry and Zawadzki 1995) can also contribute to the BB peak. After the hydrometeors are fully melted, their falling terminal velocities increase, decreasing their spatial volume concentration and resulting in a sharp decrease in reflectivity (Fabry and Zawadzki 1995; Wexler 1955; Willis and Heymsfield 1989).

Generally, the convective rain profiles are measured in the cloud core regions, where intense updrafts and downdrafts transport hydrometeors above and below the $0^{\circ} \mathrm{C}$ level and mask the features of a BB. The stratiform rain profiles are measured away from cloud core regions (i.e., far from intense convection, typically at the periphery of convective cloud systems) or during the dissipative stages of the cloud, when vertical motions are weaker and lower cloud water contents are measured (Houghton 1968; Houze 1997; Smull and Houze 1985; Sui and Li 2005). One should not confuse the rain type names with their equivalent cloud type names, since none of the profiles examined here represent nimbostratus clouds, which are common in the subtropics and midlatitudes but not in the tropical regions (Fig. 1a).
In addition to the general classification of convective and stratiform, the profiles are classified here based on their RTH to three additional subtypes: cold, mixed, and warm rain. The temperature level boundaries for each of the subtypes are summarized in Table 2 and were determined using analyses similar to those that will be in Figs. 5 and 6 (described in greater detail below). Generally, warm profiles refer to those with RTH located below the $0^{\circ} \mathrm{C}$ isotherm height (or the height for which mixed-phase hydrometeors might exist), cold profiles refer to those with RTH located above a height for which the cloud is expected to contain mostly ice, and mixed profiles refer to the intermediate heights. The temperature-level boundaries between classes are different for land (continental and island) and ocean, and for stratiform or convective cases, as seen in Table 2 . The separation to subtypes of stratiform rain profiles is similar for all region types, as can be expected since a narrow region near the $0^{\circ} \mathrm{C}$ level in the stratiform regions of deep convective clouds generally separates the liquid and glaciated parts (Smull and Houze 1985; Stith et al. 2002; Willis and Heymsfield 1989). The separation to subtypes of convective rain profiles are consistent with previous work that found much lower glaciation temperatures for clouds over land, occasionally reaching near the homogeneous freezing level $\left(\sim-40^{\circ} \mathrm{C}\right.$; Rosenfeld and Woodley 2000; Williams E. et al. 2002; Yuan et al. 2010).

\section{Results and discussion}

\section{a. Reflectivity profiles sorted by $R T H$}

When averaged together as a function of RTH, a consistent behavior of the reflectivity profiles emerges. In Fig. 2, reflectivity profiles for each of the 12 tropical regions [four over ocean (blue), four over continents (red), and four over large islands (green); see Fig. 1a] were sorted and averaged according to RTH. As expected for regions located within the ITCZ belt, the mean temperature profiles (see right-hand-side $y$ axis) are almost identical up to at least $15 \mathrm{~km}$ for all regions. Sorting by RTH yields a clear separation between the average profiles, with no overlaps (i.e., for a given height in the atmosphere, the reflectivity at that height is higher for profiles with higher tops).

An obvious consequence is that as RTH increases, the average near-surface reflectivity monotonically increases as well. Also noticeable are the different shapes (slopes) of profiles in different layers, which are further explored below. The characteristic shapes of reflectivity profiles have been used in the past as the basis for correction of surface rainfall measurements at far distances 

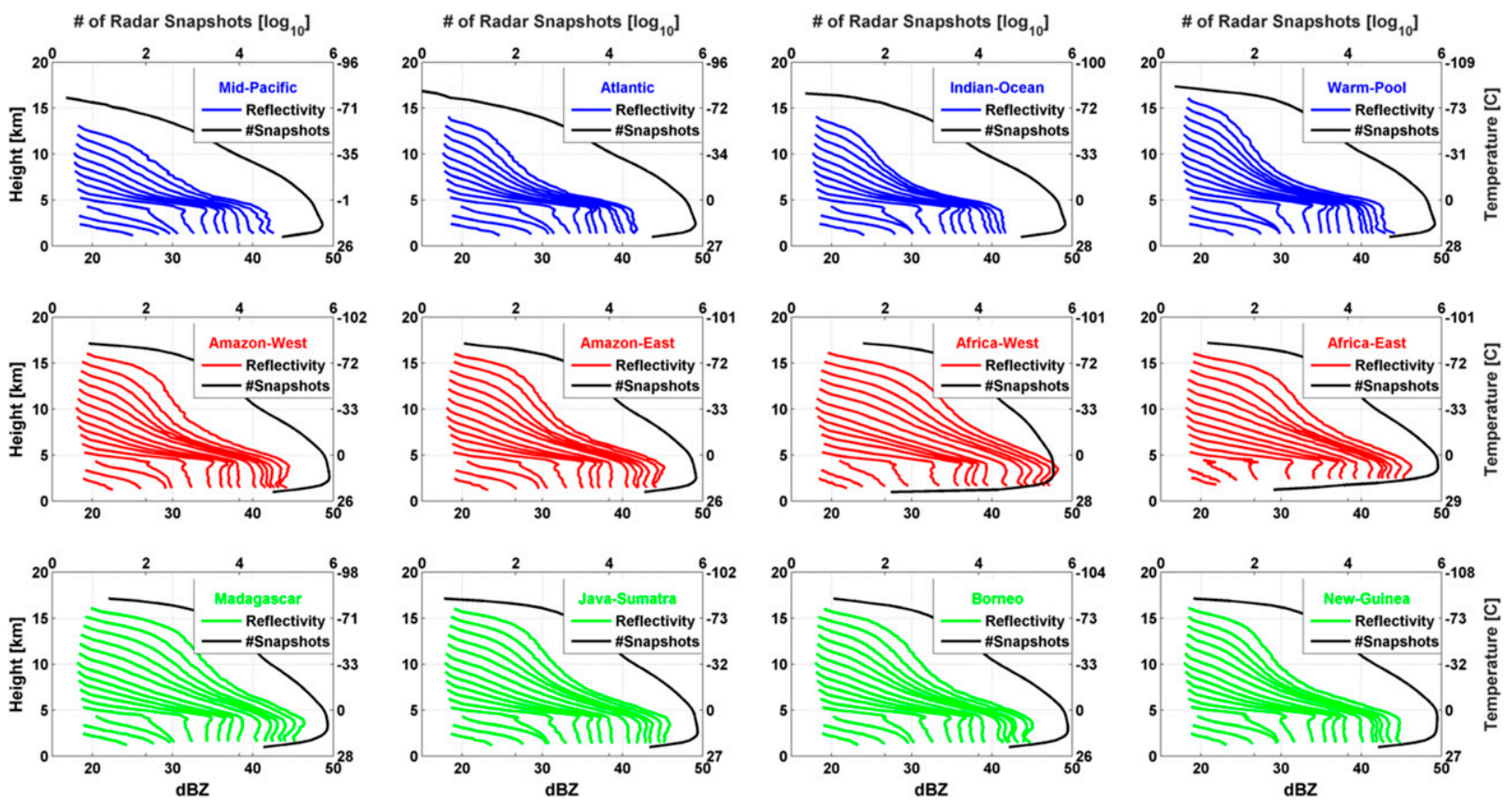

FIG. 2. Mean vertical profiles of radar reflectivity (dBZ; colored lines), sorted and averaged as a function of RTH, with vertical binning resolution of $1 \mathrm{~km}$. A minimum of 250 profiles per RTH was imposed on the data. The panels correspond to the regions defined in Fig. 1a (line colors correspond to box colors in Fig. 1), with region names included in the legends. Temperature $\left({ }^{\circ} \mathrm{C}\right)$ corresponding vertical scales are displayed on the right-hand side of each panel. Also included are total radar counts as a function of height ( $\log _{10}$ units; black lines). Notice the sharp decrease in radar counts below $\sim 2 \mathrm{~km}$, where much of the data are excluded to avoid surface clutter issues.

from ground radars (Andrieu and Creutin 1995; Vignal et al. 1999). However, these studies have not considered the dependence of characteristic profiles on their RTH. For all regions, the number of total samples (i.e., including all RTHs) available per height increases with decreasing height up to about $\sim 2.5 \mathrm{~km}$, where a decrease in sample statistics is seen because of the exclusion of off-nadir profile data at those heights. The decrease in samples occurs at higher heights for regions with elevated topography (e.g., Africa-East, Madagascar, and New Guinea).

It can be seen that the amount of high RTH profile statistics varies from region to region. Continental and island regions have sufficient statistics up to $16 \mathrm{~km}$ (slightly below the tropopause height), while oceanic region profiles (except the Warm Pool) only reach up to 13-14 km. Comparison of meteorological parameters for all regions (see Table 1) shows a general similarity for most parameters [e.g., relative humidity, precipitable water, and effective LCL height (i.e., mean LCL height minus mean elevation height)] between the regions. However, a few distinct differences are noticed: 1) oceanic regions have lower mean relative humidity above the $0^{\circ} \mathrm{C}$ height; 2) continental regions have higher means and variances of CAPE and effective LCL values, but lower means of large-scale midatmospheric vertical velocity; and 3) despite having the largest variance in topography, island regions tend to show intermediate values (i.e., between oceanic and continental) for most parameters.

We next perform rain data classification to convective and stratiform rain types. Rain type statistics (including cold, mixed, and warm subtypes) are summarized in Table 3. For all regions, at least two-thirds of profiles are of stratiform type, with most profiles being of stratiform cold type, and the least of stratiform warm type. The dominance of stratiform rain statistics increases for continental and island regions, reaching up to $80 \%$ of profiles for Africa-East. The convective profiles are dominated by warm type profiles for oceanic regions (indicating the prevalence of shallow isolated convection over the oceans; Schumacher and Houze 2003) and mixed type profiles for the other regions. Cold convective type accounts for only a few percent of all profiles.

Taken as case studies for the oceanic, continental, and island regions, data from the Atlantic, Africa-West, and Madagascar regions are sorted and averaged by RTH at 250-m intervals and divided into stratiform (Fig. 3) and convective (Fig. 4) rain types. All 12 regions were analyzed (not shown here) and are well represented by the case studies. The average stratiform profile plots (Fig. 3) for all three regions appear very similar to one another. 
TABLE 3. Percent of profiles per rain type. The percent is with respect to total amount of nonintermittent profiles with positive estimated surface rain. Rain types include stratiform cold $\left(\mathrm{St}_{C}\right)$, mixed $\left(\mathrm{St}_{M}\right)$, and warm $\left(\mathrm{St}_{W}\right)$; convective cold $\left(\mathrm{Con}_{C}\right)$, mixed $\left(\mathrm{Con}_{M}\right)$, and warm $\left(\mathrm{Con}_{W}\right)$; and other as defined in the TRMM $2 \mathrm{~A} 23$ product.

\begin{tabular}{lrrrrrrr}
\hline & \multicolumn{7}{c}{ Rain type statistics (\%) } \\
\cline { 2 - 8 } \multicolumn{1}{c}{ Region } & $\mathrm{St}_{C}$ & $\mathrm{St}_{M}$ & $\mathrm{St}_{W}$ & $\mathrm{Con}_{C}$ & $\mathrm{Con}_{M}$ & $\mathrm{Con}_{W}$ & Other \\
\hline Mid-Pacific & 25.5 & 24.5 & 15.4 & 2.0 & 6.5 & 26.0 & 0.1 \\
Atlantic & 28.5 & 25.6 & 11.9 & 2.5 & 10.8 & 20.6 & 0.1 \\
Indian Ocean & 30.9 & 27.0 & 11.0 & 2.7 & 9.2 & 19.0 & 0.2 \\
Warm Pool & 32.4 & 23.7 & 11.8 & 3.3 & 9.7 & 19.1 & $<0.1$ \\
Amazon-West & 38.8 & 30.2 & 7.7 & 1.3 & 13.4 & 8.6 & $<0.1$ \\
Amazon-East & 35.3 & 29.2 & 8.4 & 1.6 & 14.5 & 10.9 & $<0.1$ \\
Africa-West & 44.6 & 24.0 & 2.2 & 5.9 & 19.9 & 3.4 & $<0.1$ \\
Africa-East & 42.2 & 35.0 & 2.2 & 2.0 & 15.9 & 2.7 & $<0.1$ \\
Madagascar & 36.6 & 28.8 & 6.6 & 2.5 & 15.7 & 9.8 & $<0.1$ \\
Java-Sumatra & 37.4 & 26.1 & 8.0 & 1.6 & 15.8 & 11.1 & $<0.1$ \\
Borneo & 37.7 & 30.2 & 7.0 & 1.2 & 15.0 & 8.9 & $<0.1$ \\
New Guinea & 41.6 & 29.0 & 6.6 & 1.3 & 13.7 & 7.8 & $<0.1$ \\
\hline
\end{tabular}

Similar to Fig. 2, profiles originating from different RTHs show non-overlapping manifolds at all levels except for high RTH profiles around the BB region (slightly below the $0^{\circ} \mathrm{C}$ level, $\sim 4.8 \mathrm{~km}$ ), where BB effects dominate the reflectivity signal and the profiles converge to similar peak reflectivity values. Nonetheless, above and below the BB layer, the separation in reflectivity between average profiles is generally retained.

The cold, mixed, and warm type profiles are marked in blue, magenta, and red, respectively. For cold stratiform profiles, there is a relatively weak increase in reflectivity with decreasing height until a sharp increase around the $-5^{\circ} \mathrm{C}$ level followed by the $\mathrm{BB}$ region. Below the $\mathrm{BB}$ region (below $\sim 3.5 \mathrm{~km}$ ) slight interregional differences are seen, where the oceanic region shows consistent increase in reflectivity while the continental and island regions show relatively constant reflectivity, varying from weak decreases to weak increases. In addition, sufficient statistics for cold stratiform profiles extend up to $\sim 1 \mathrm{~km}$ higher over land (continental and island) regions. The warm stratiform profiles show monotonic reflectivity increase with decreasing height, with the magnitude of increase highest at top and lowest at the bottom. The mixed type profiles present a transition between cold type and warm type behaviors, as RTH decreases. Also included are histograms of RTH counts (Figs. 3d,e) showing a unimodal (bimodal) shape with a peak at $5.5 \mathrm{~km}$ (3.25 and $5.25 \mathrm{~km}$ ) for land (oceanic) regions.

The average convective profiles are shown in Fig. 4 and exhibit manifold separation at all levels and for all regions. The cold convective profiles can be separated to three main segments with respect to decreasing height:
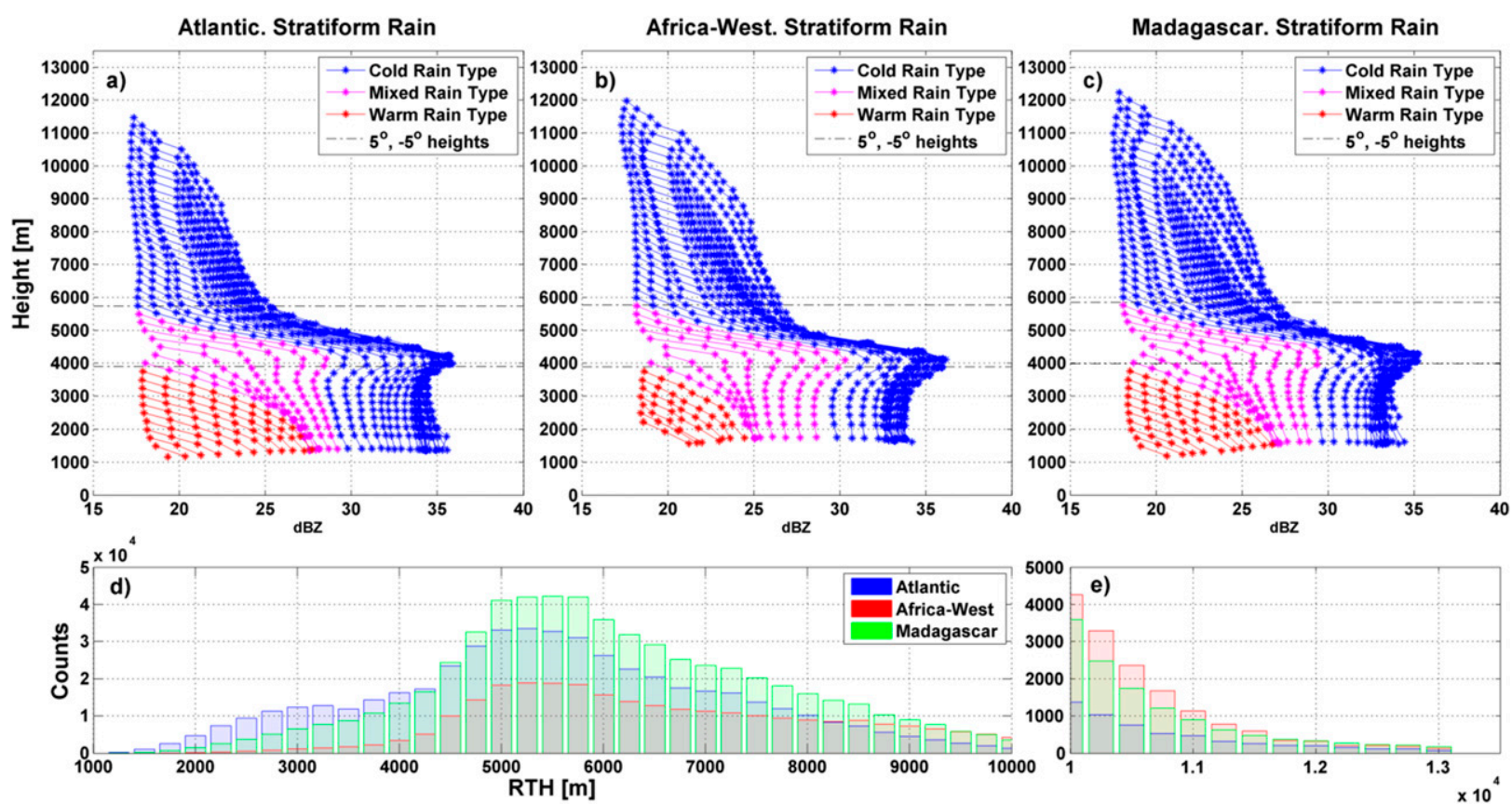

FIG. 3. Case study comparison of stratiform rain type reflectivity profiles, sorted and averaged as a function of RTH, with vertical binning resolution of $0.25 \mathrm{~km}$. Case studies include (a) Atlantic (oceanic region), (b) Africa-West (continental region), and (c) Madagascar (island region). Blue, magenta, and red colors refer to cold, mixed, and warm type profiles as classified in section 2c, with horizontal dashed-dotted lines marking the transition between the different types. (d) Histogram of profiles per RTH for the case study regions; (e) heights $>10 \mathrm{~km}$ portion of the histogram is magnified. 

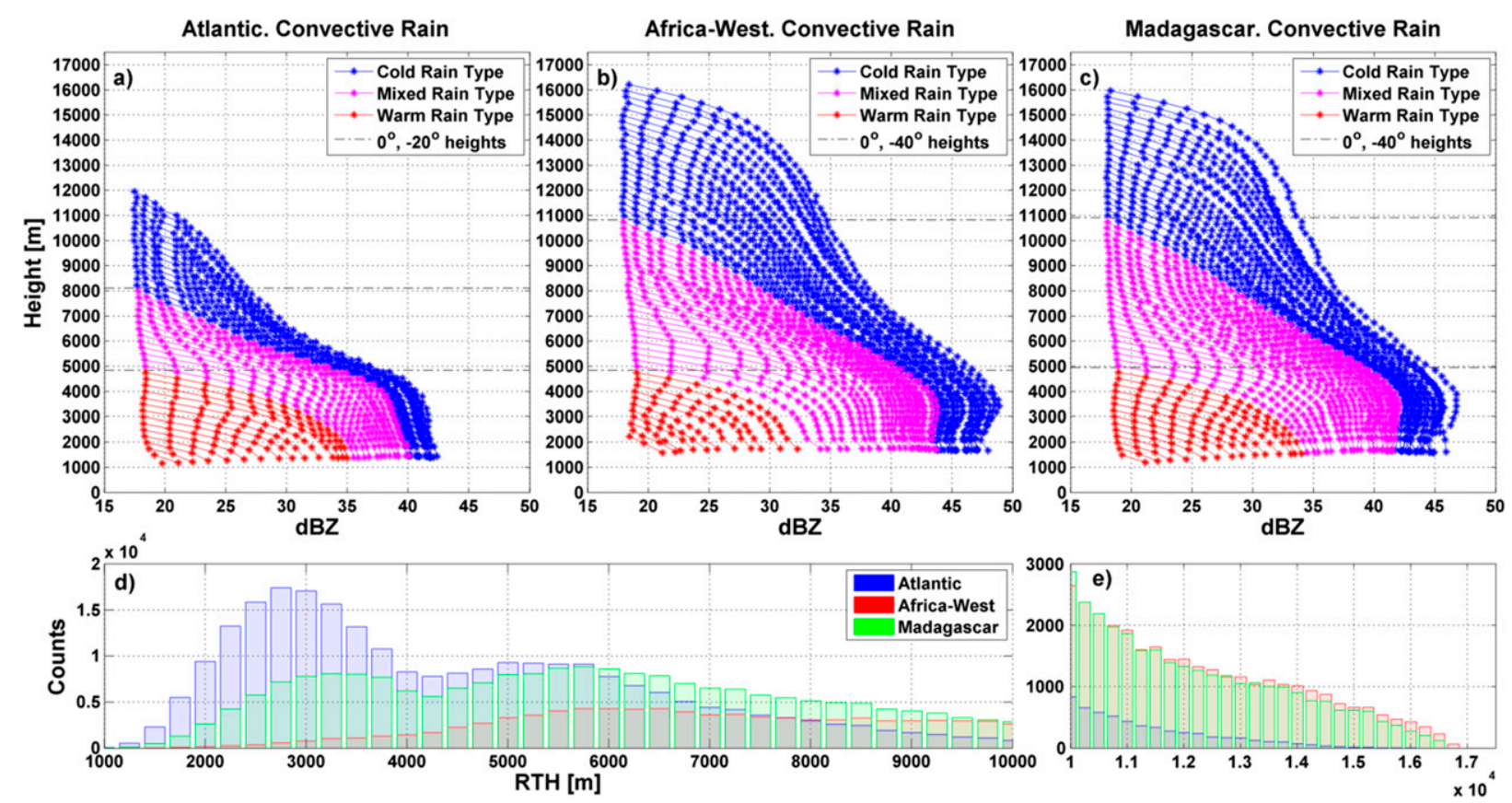

FIG. 4. As in Fig. 3, but for convective rain type.

moderate reflectivity increase between the RTH and the $-20^{\circ} \mathrm{C}$ height, strong increase between the $-20^{\circ}$ and $0^{\circ} \mathrm{C}$ heights (that also incorporates smoothed $\mathrm{BB}$ effects near the $0^{\circ} \mathrm{C}$ height), and weak increase or decrease below the $0^{\circ} \mathrm{C}$ height. The warm convective profiles have similar behavior to the warm stratiform ones (see section $2 \mathrm{c}$, nonisolated warm profiles are separated to stratiform and convective types on the basis of reflectivity magnitude), and again the mixed type profiles show a gradual transition from cold to warm.

The interregional differences for convective type profiles are similar to those seen for stratiform type, but are much more pronounced. The Africa-West and Madagascar (land regions) show increased high RTH statistics compared with the Atlantic (oceanic) region, with average profiles reaching $4 \mathrm{~km}$ higher. The RTH histograms (Figs. 4d,e) also show a transition from being warm rain dominated in the oceanic region to mixed rain dominated in the continental region. The island RTH histogram appears to be a superposition of the other two. As opposed to the oceanic cold convective profiles, which show an increase in reflectivity with decreasing height below the $0^{\circ} \mathrm{C}$ height, the other regions show a decrease in reflectivity for the majority of that section, as found in other work (Hirose and Nakamura 2004; Liu and Zipser 2013). Last, the mixed-phase transition region is much deeper (between the $-40^{\circ}$ and $0^{\circ} \mathrm{C}$ levels) for the nonoceanic regions. All these differences are consistent with stronger and deeper convection over land areas (Rosenfeld and Lensky 1998; Williams E. and Stanfill 2002; Zipser and Lutz 1994), which in turn can deepen the mixed-phase region in the cloud. Convective intensity over land can also be linked to higher effective LCL heights and CAPE values (see Table 1). Higher effective LCL heights imply higher cloud bases (Craven et al. 2002; Meerkötter and Bugliaro 2009), which in turn imply increased vertical velocities (Zheng and Rosenfeld 2015; Zheng et al. 2015).

It should be noted that both stratiform and convective cold and mixed profiles show relatively rapid increase in reflectivity for the first $\sim 1 \mathrm{~km}$ below the RTH (seen especially between 1 and $1.25 \mathrm{~km}$ below the RTH in Figs. 3,4$)$ with a scale break to weaker reflectivity increase below. As shown in the next section, the results for the first $\sim 1.25 \mathrm{~km}$ of the cold rain profiles may be affected by a consistent artifact and should be treated with caution.

\section{b. Consistency of reflectivity slopes}

The near-parallel average profile lines per specific rain type in Figs. 2-4 give rise to the assumption that average rain profiles follow similar hydrometeor growth pathways per rain type. On average, a population of hydrometeors initiated at a higher RTH will have more distance (and hence more time) to fall, grow, and eventually reach the surface with a higher reflectivity signature. To test this assumption, we examine reflectivity slope $\left(\mathrm{dBZ} \mathrm{km}^{-1}\right)$ profiles sorted by RTH at 

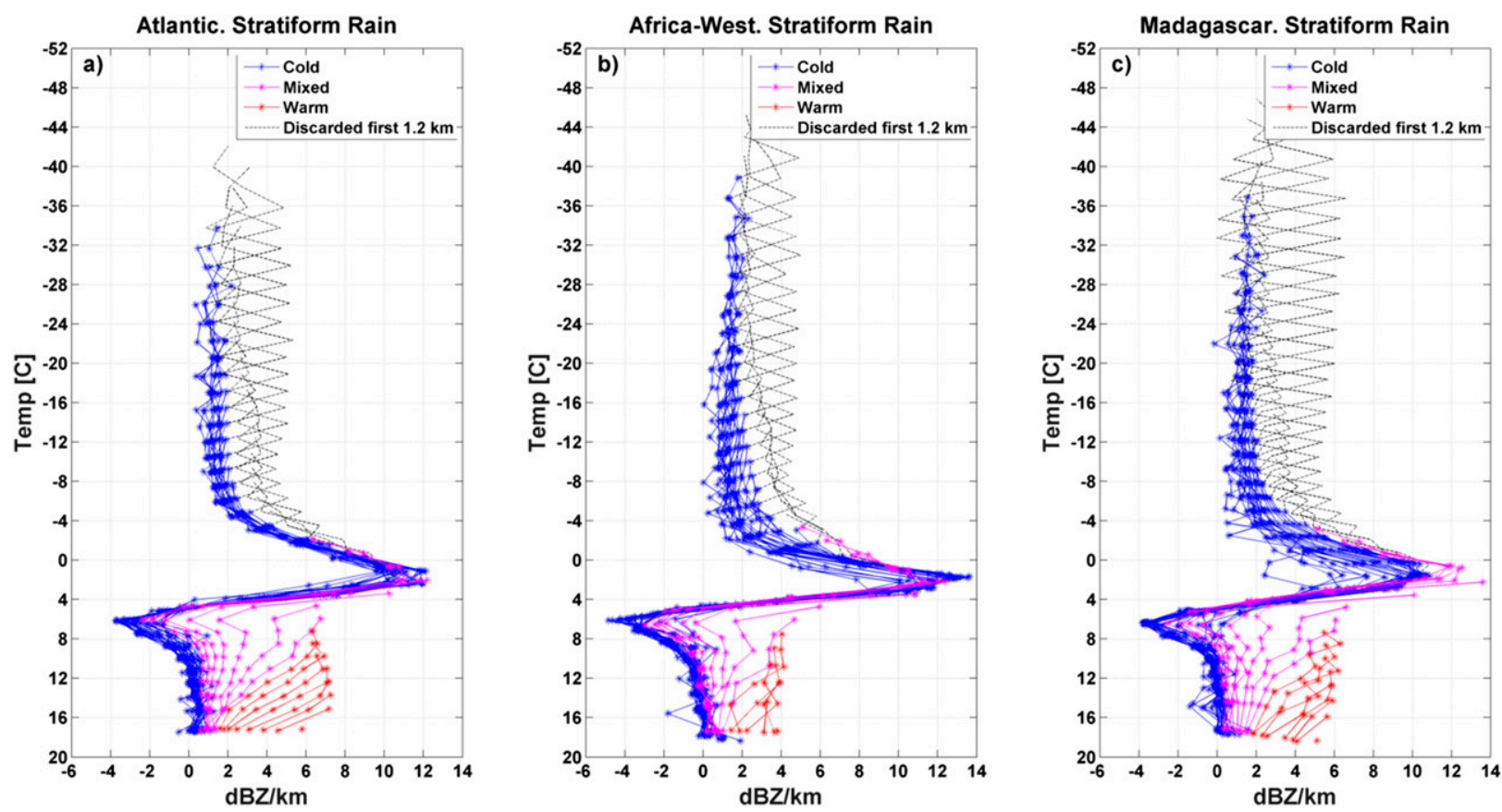

FIG. 5. Stratiform rain type mean vertical profiles of reflectivity slopes $\left(\mathrm{dBZ} \mathrm{km}{ }^{-1}\right)$ for chosen case studies. Slopes correspond to the derivatives of the mean profiles in Fig. 3. Profiles are divided to cold, warm, and mixed subtypes (see line descriptions in legends). First $1.2 \mathrm{~km}$ of profiles with RTH above $-5^{\circ} \mathrm{C}$ are labeled with dashed lines and are excluded from later analyses.

250-m intervals for the case study regions of section 3a and for stratiform (Fig. 5) and convective (Fig. 6) rain types separately. Only temperature is used here as the vertical scale, as hydrometeor growth processes and phase transitions depend on temperature and not the actual atmospheric altitude. Additionally, as performed above, profiles are divided (different line colors) into cold, mixed, and warm subtypes as specified in Table 2.

We note the existence of a local reflectivity slope spike $750 \mathrm{~m}$ below the profile top height (i.e., fourth point from top) for both stratiform and convective profiles with RTH above the $\sim-5^{\circ} \mathrm{C}$ isotherm height. A comparison to slope profile data from the new GPM satellite level $2 \mathrm{Ku}$-band product [similar to TRMM with sensitivity of $\sim 18 \mathrm{dBZ}$ (Hou et al. 2014; Iguchi et al. 2010); see Fig. S1 in the supplemental material for details] indicates that the main discrepancy between TRMM and GPM is for the first $1.2 \mathrm{~km}$ of the profiles, where the slope peak does not exist in the GPM data. The GPM data, however, are in their initial stages of validation, and further work is needed to understand the discrepancies between both satellites. Because of these uncertainties, we shall consider the first few samples of the data as uncertain. We therefore mark the first $1.2 \mathrm{~km}$ of slope profiles with dashed lines to highlight profile sections that are discarded hereafter. For more details on the slope peak, see Figs. S1 and S2 in the supplemental material.
In Fig. 5 all cold stratiform reflectivity slope profiles (RTH located above the $-5^{\circ} \mathrm{C}$ isotherm height) nearly converge to a single reflectivity slope profile, irrespective of their RTH. The BB area shows larger variance between profiles, as expected when the derivatives in the slope profile are very large. The convergence is seen for all regions, but the variance in slope pathways of different $\mathrm{RTH}$ is smallest for the oceanic region. It is important to note that this convergence of reflectivity slopes to similar values by profiles initiated at different heights does not imply an identical growth rate per temperature/ height for all profiles. A constant logarithmic derivative \{i.e., $\left[\partial\left(\log _{10} Z\right) / \partial H\right] \propto(1 / \bar{D})(\partial \bar{D} / \partial H)$; see the appendix implies exponential increase of the growth rate with distance traveled by an average hydrometeor. In other words, a hydrometeor of diameter $2 \mathrm{~mm}$ must grow 4 times more than a $0.5-\mathrm{mm}$ diameter hydrometeor per kilometer distance for both hydrometeors to maintain the same local reflectivity slope. A quantitative analysis of the convergence of cold rain reflectivity slope profiles is performed below.

The warm stratiform rain profiles (RTH located below the height of the $5^{\circ} \mathrm{C}$ isotherm) do not converge to a single slope pathway, but they do show a consistent behavior, especially for the oceanic region: a monotonic decrease in slope value with the decrease in height (increase in temperature), starting at about $5-7 \mathrm{dBZ} \mathrm{km}^{-1}$ and ending at smaller, positive values. Nearly parallel 

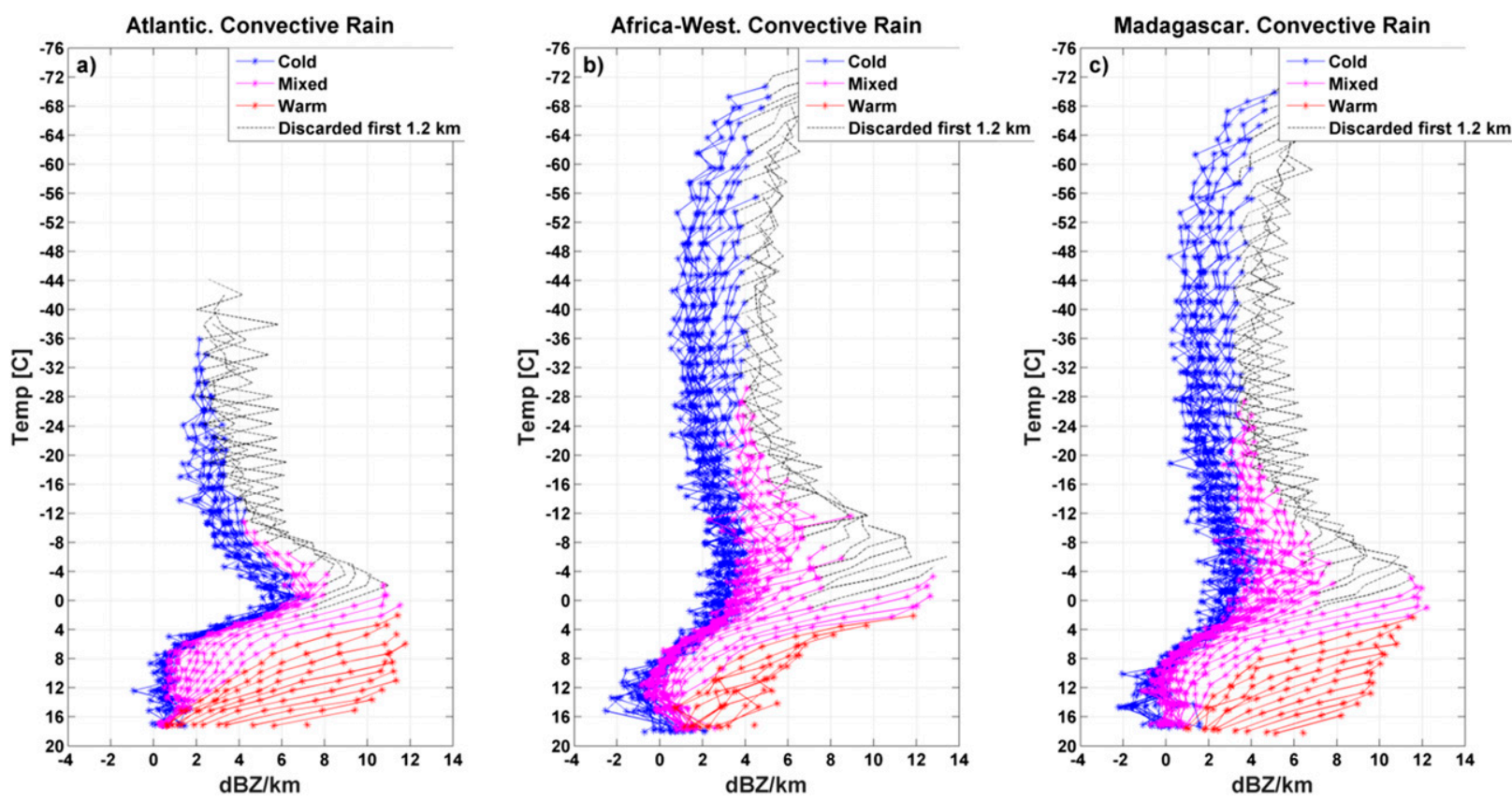

FIG. 6. As in Fig. 5, but for convective rain type.

reflectivity slope profiles are seen for the warm rain type profiles in the other oceanic regions as well. Warm stratiform rain for continental and island regions show a similar decreasing slope behavior but their slope profiles are much noisier, possibly due to much lower statistics (see Fig. 5c) or due to a larger natural variation in the thermodynamical conditions associated with nonisolated stratiform warm rain over land. As described in the previous section, the mixed type profiles (RTH located between the $-5^{\circ}$ and $5^{\circ} \mathrm{C}$ heights) show a transition between the cold and warm rain type behaviors. The transition is clearly demonstrated in Fig. 5, where the highest mixed type slope profile resembles the typical cold rain slope profile and the lowest one resembles the typical warm rain slope profile. This illustrates how the temperature boundary values in Table 2 were derived, by observing the temperatures where transitions in slope profile behavior occur.

The convective rain slope profiles for the three case study regions are shown in Fig. 6. Several interregional similarities can be pointed out. All regions tend to show convergence of the cold rain profiles (RTH located above the $-20^{\circ}$ and $-40^{\circ} \mathrm{C}$ heights for oceanic and land regions, respectively), to a nearly unique reflectivity slope profile. The variance between these different RTH profiles is smaller lower in the atmosphere, especially below the height of the $0^{\circ} \mathrm{C}$ isotherm. Above the melting level, slope profiles show positive values ranging from 0 to $6 \mathrm{dBZ} \mathrm{km}^{-1}$, whereas below the melting level, slope values are positive and nearly constant $\left(\sim 0.5 \mathrm{dBZ} \mathrm{km}^{-1}\right)$ for the oceanic regions but fluctuate from negative to positive (from $\sim-2$ to $2 \mathrm{dBZ} \mathrm{km}^{-1}$ ) for land regions. The warm slope profiles (RTH below $0^{\circ} \mathrm{C}$ ) show similar behavior to their stratiform counterparts, but start from much larger slope values $\left(\sim 9-12 \mathrm{dBZ} \mathrm{km}^{-1}\right)$ and show a clear monotonic slope decrease with decreasing height for all regions. As expected, the mixed type convective profiles show a gradual transition from cold to warm behavior for all regions. This transition region reaches much lower temperatures for the continental and island regions, illustrating the large differences seen between oceanic and land regions for convective type profiles.

In fact, because of the larger variance for the cold rain slope profiles above the $-30^{\circ} \mathrm{C}$ height in land regions, it is hard to set a clear boundary to where cold profiles behavior starts to shift to mixed type profiles. This is to be expected in land regions where intense convective (and possibly increased aerosol amounts) may increase supercooled water and mixed-phase particle fluxes to higher altitudes, delay ice formation, and widen the mixed-phase layer (Rosenfeld 2000; Rosenfeld and Woodley 2000; Williams E. et al. 2002; Zipser and Lutz 1994). Thus, the upper boundary of the $-40^{\circ} \mathrm{C}$ isotherm was taken for the land mixed rain type. It corresponds to the homogeneous freezing height (Pruppacher 1995), where above it profiles are likely to contain only ice processes.

\section{c. Cold rain slope profiles}

The significant similarities between the cold rain reflectivity slope profiles originating at different RTHs 

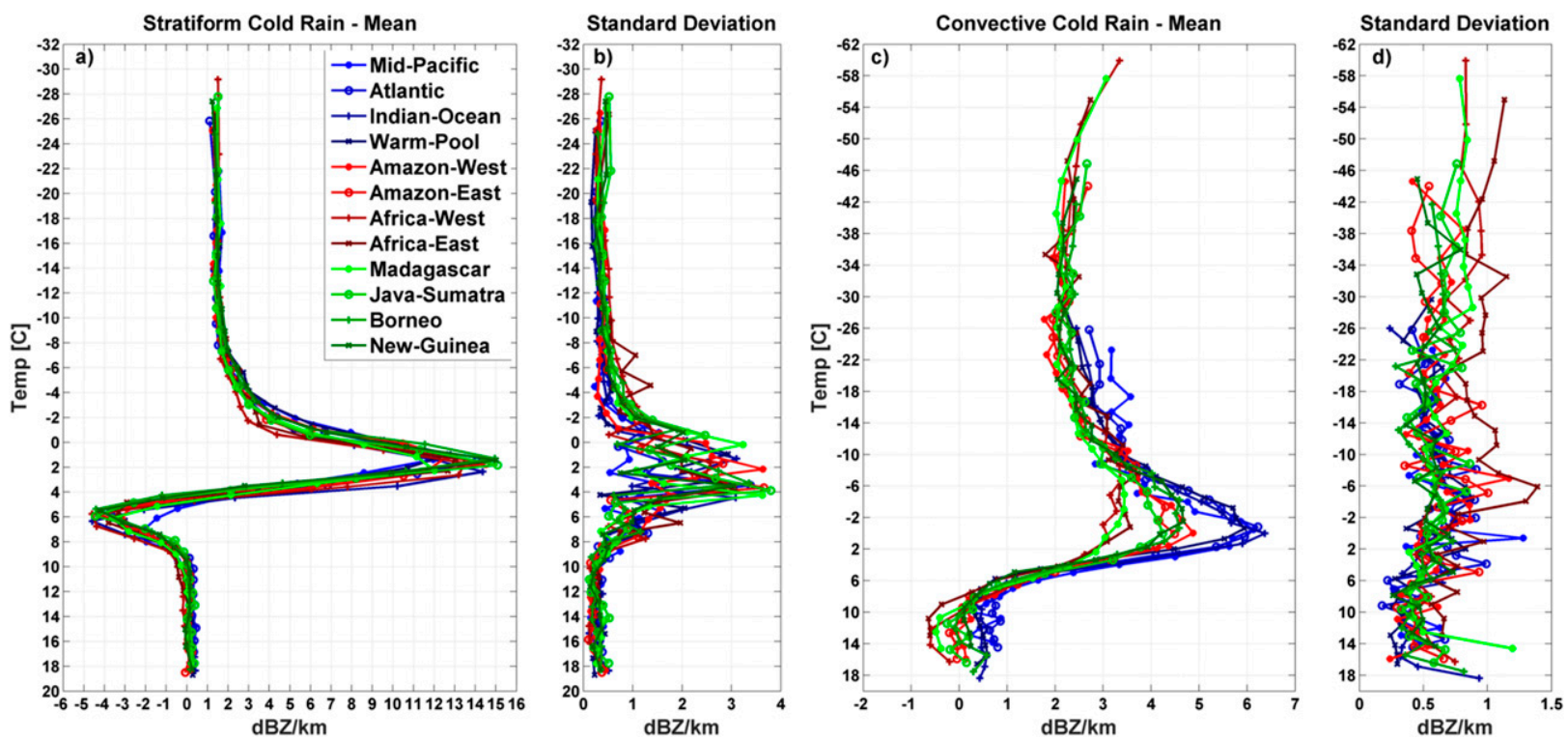

FIG. 7. (a),(c) Mean and (b),(d) std dev of cold rain reflectivity slope profiles $\left(\mathrm{dBZ} \mathrm{km}{ }^{-1}\right)$ as a function of temperature $\left({ }^{\circ} \mathrm{C}\right)$ for all 12 regions in Fig. 1a (see legend for line description). Data are divided to (a),(b) stratiform and (c),(d) convective rain types. Interregional differences are much more prominent for convective rain type.

(blue lines in Figs. 5, 6) suggest emergence of a universal behavior of hydrometeor growth that can be described by a characteristic slope profile. Cold rain profiles comprise between $25 \%$ and $50 \%$ of all profiles (see Table 3 ), so a significant portion of the data can be represented by characteristic profiles. We note a weak dependence of the average cold rain profiles on the radar incidence angle (not shown here), yielding higher average reflectivity per height below the melting level (up to $2 \mathrm{dBZ}$ ) for nadir profiles compared with swath edge profiles. These effects are most prominent for stratiform type profiles with incidence angles larger than $8.5^{\circ}$. Therefore, to obtain the most accurate cold rain profiles while maintaining sufficient statistics, we limit the analyses of this section to the center half of incidence angles (i.e., rays $0-12$, or angles smaller than $8.5^{\circ}$ ). This constraint reduces the number of profiles considered by about $50 \%$.

The average cold rain profiles for all regions are shown in Fig. 7. An outstanding finding is seen for stratiform rain (Fig. 7a), where the average reflectivity slope profiles of all regions nearly overlap each other. As a measure of the significance of the average cold rain slope profile, the variance (between slope values of different RTH profiles) per temperature is plotted in Fig. 7b. The largest variance values (up to $4 \mathrm{dBZ} \mathrm{km}^{-1}$ ) are between $-8^{\circ}$ and $8^{\circ} \mathrm{C}$ temperature levels (Fig. 7a), corresponding to the region where transitions in reflectivity slopes occur, as seen in Fig. 5. Below and above this region the variance is much lower and stable at around $0.3 \mathrm{dBZ} \mathrm{km}^{-1}$.
The average cold rain stratiform profile can be divided to three distinct regions: 1 ) above the $-12^{\circ} \mathrm{C}$ isotherm height, where a constant slope of $\sim 1.5 \mathrm{dBZ} \mathrm{km}{ }^{-1}$ is seen; 2) between the $-12^{\circ}$ and $10^{\circ} \mathrm{C}$ heights, where slope values shift considerably because of the $\mathrm{BB}$ and localized microphysical effects (e.g., aggregation of snow, hydrometeor phase changes, and changes in volume concentration and particle density), showing exponential slope increase from the $-12^{\circ} \mathrm{C}$ height to the positive maximal peak of $10-15 \mathrm{dBZ} \mathrm{km}^{-1}$ at $\sim 2^{\circ} \mathrm{C}$ height, followed by a sharp decrease in slope values to a negative peak of $-5 \mathrm{~dB} Z \mathrm{~km}^{-1}$ at the $\sim 6^{\circ} \mathrm{C}$ height; and 3) below the $10^{\circ} \mathrm{C}$ height, where the slope is neutral to slightly positive $\left(\sim 0-0.5 \mathrm{dBZ} \mathrm{km}^{-1}\right)$ until the profile bottom.

Specifically, the increase in slope value between the $-12^{\circ}$ and $0^{\circ} \mathrm{C}$ heights is unlikely to be attributed to melting or ice hydrometeor density changes (Johnson et al. 2012), but rather to more efficient ice hydrometeor growth processes, such as aggregation of ice particles (Smull and Houze 1985; Stith et al. 2002; Willis and Heymsfield 1989). Aggregation is known to occur mainly in temperatures warmer than $-12^{\circ} \mathrm{C}$ and increase in efficiency as the $0^{\circ} \mathrm{C}$ level is approached (Hosler et al. 1957; Mitchell 1988). Above the $-12^{\circ} \mathrm{C}$ height and below the $10^{\circ} \mathrm{C}$ height, the small reflectivity slopes indicate weaker growth processes. This could be due to a combination of reasons discussed above, such as inefficient ice-ice processes (at high altitudes), balance between collection and breakup (at low altitudes), or 

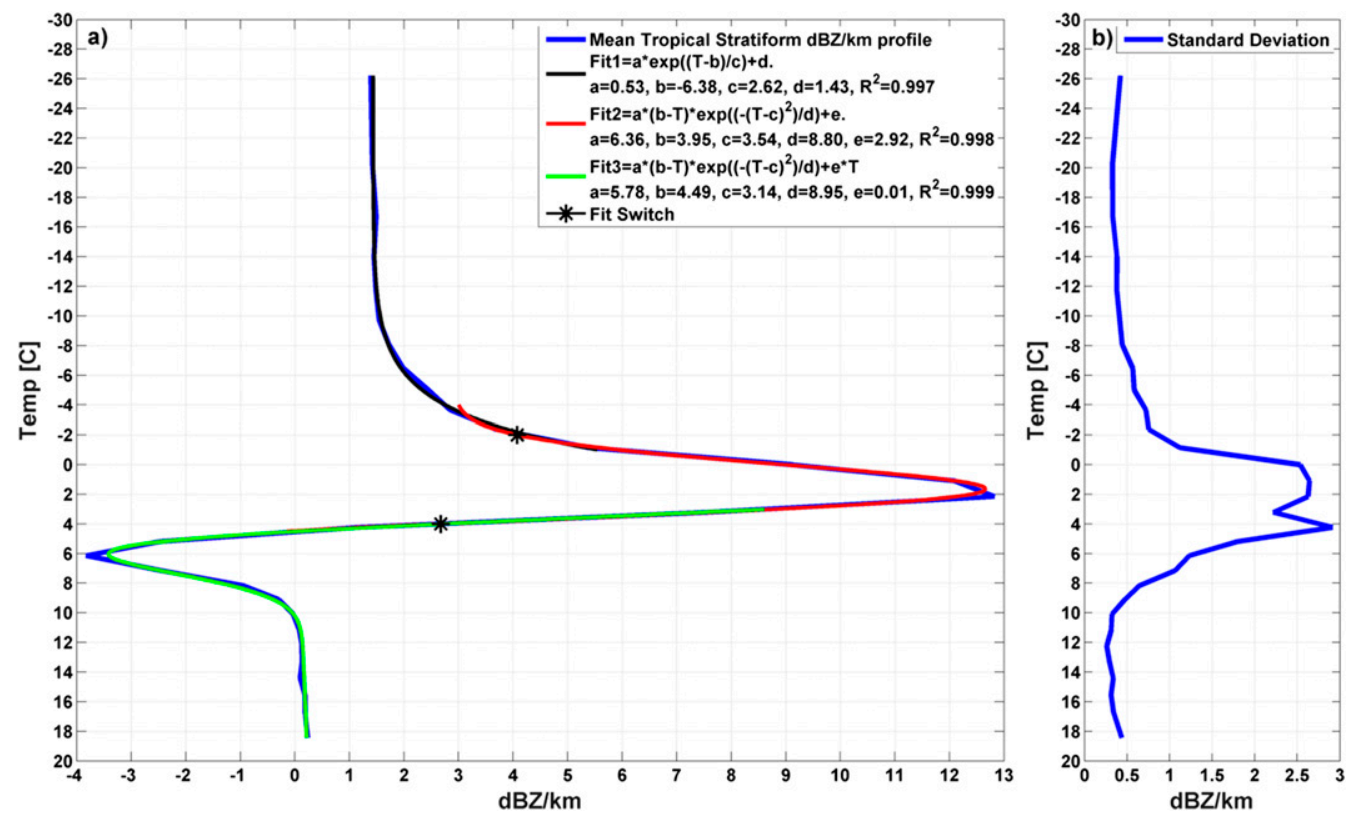

FIG. 8. (a) Mean tropical stratiform cold rain reflectivity slope profile ( $\mathrm{dBZ} \mathrm{km} \mathrm{km}^{-1}$; blue curve) as a function of ambient temperature $\left({ }^{\circ} \mathrm{C}\right)$. The profile was composed by averaging all regions and all RTH cold rain stratiform profiles together and taking the derivative. (b) The corresponding std dev profile. The mean slope profile can be well represented by an exponential fit for temperatures lower than $-2^{\circ} \mathrm{C}$ (black curve), and two fits of Gaussian derivatives for higher temperatures: one between $-2^{\circ}$ and $4^{\circ} \mathrm{C}$ (red curve) and one for temperatures above $4^{\circ} \mathrm{C}$ (green curve). Fit details and coefficient values are included in the figure legend.

low CWC values throughout most of the stratiform vertical.

The minor differences between the stratiform profiles of oceanic, continental, and island regions suggest that the typical land-ocean differences in convection and microphysics take place mostly in the cloud cores and not clouds' and cloud systems' margins. We can assume that stratiform rain processes (away from the convective core) in deep clouds with cold rain depend mainly on the temperature and CWC profiles of the clouds and less on convective intensity and drop size distributions, which are more relevant to the rain development in the cloud's core. Since the tropical temperature profiles (see Fig. 2) are very similar for all regions, we can conclude that the CWC profiles of the cloud margins are very similar as well, even though they may be very different in the cloud cores. In Fig. 8a the stratiform, cold rain slope profiles from all the regions are averaged together to get a mean tropical ITCZ representative slope profile. It can be well fit by exponential growth above the $\mathrm{BB}$ region and two Gaussian derivative functions below, depending only on temperature, as follows:

$$
\begin{aligned}
& \operatorname{slope}(T)\left(\frac{\mathrm{dB} Z}{\mathrm{~km}}\right)=a \exp ^{(T-b) / c}+d, \text { for } T<-2^{\circ} \mathrm{C}, \\
& \operatorname{slope}(T)\left(\frac{\mathrm{dB} Z}{\mathrm{~km}}\right)=a(b-T) \exp ^{-\left[(T-c)^{2}\right] / d}+e, \text { for } T>-2^{\circ} \text { and } T<4^{\circ} \mathrm{C}, \text { and } \\
& \operatorname{slope}(T)\left(\frac{\mathrm{dB} Z}{\mathrm{~km}}\right)=a(b-T) \exp ^{-\left[(T-c)^{2}\right] / d}+T e, \text { for } T>4^{\circ} \mathrm{C},
\end{aligned}
$$

where $T$ is the temperature and the coefficient values are shown in the legend of Fig. 8a. The corresponding reflectivity slope standard deviation profile is shown in Fig. 8b. According to the fit, above the altitude of the $-12^{\circ} \mathrm{C}$ isotherm we have a nearly constant growth rate of $1.43 \pm 0.45 \mathrm{dBZ} \mathrm{km}^{-1}$ [implies average hydrometeor growth by $4.8 \% \mathrm{~km}^{-1}$, see Eq. (A4)], and below the $10^{\circ} \mathrm{C}$ height there is a weak increase of slope from $0 \pm 0.35 \mathrm{dBZ} \mathrm{km}^{-1}$ to a maximum of $0.2 \pm$ $0.45 \mathrm{~dB} Z \mathrm{~km}^{-1}$ at the surface. Such a fit can be used for 
comparison with measured data by other instruments, for validation of numerical models results, or for validation of physically based models of stratiform cold rain profiles (e.g., Awaka et al. 1985; Kirstetter et al. 2013a).

Contrary to the stratiform case, the average cold rain slope profiles for convective rain (Fig. 7c) show significant interregional differences. The standard deviations per region (Fig. $7 \mathrm{~d}$ ) are generally slightly larger (range about $0.25-1.4 \mathrm{dBZ} \mathrm{km}^{-1}$ ) than in the stratiform case except in the vicinity of the $\mathrm{BB}$ region, indicating larger sensitivity of the cold rain slope profiles to changes in RTH. It can be seen that the continental and island profiles reach higher in the atmosphere (significant statistics up to $-60^{\circ} \mathrm{C}$ ) than the oceanic regions profiles $\left(\sim-30^{\circ} \mathrm{C}\right)$. The shift of continental profiles to higher altitudes is in line with expectation for stronger updrafts, higher cloud bases (Jorgensen and LeMone 1989; Williams E. and Stanfill 2002), and the elevated topography for continental and island regions (see Table 1).

As seen in previous work (see section 1), the oceanic regions consistently show larger reflectivity slope values throughout the vertical profile, peaking at (5.5-6.5) \pm $0.5 \mathrm{dBZ} \mathrm{km}{ }^{-1}$ compared to $(3.5-5) \pm 0.5 \mathrm{dBZ} \mathrm{km}^{-1}$ for the land regions. Above the $-20^{\circ} \mathrm{C}$ height, where we expect mostly ice-ice processes to occur, slopes of $(2-3.5) \pm(0.5-1) \mathrm{dBZ} \mathrm{km}^{-1}$ are seen for all regions. Increasing variance with height is seen at those levels, more so for regions inclined to stronger convection. We note that the mid-Pacific region is anomalous compared to the rest above $-10^{\circ} \mathrm{C}$, showing the highest slope values. This may be another indication for relatively weaker convection for this region and is consistent with its lowest LCL and CAPE values in Table 1 . Below the $10^{\circ} \mathrm{C}$ height, where only warm processes are expected, we see slightly positive slopes for the oceanic regions $(0-1) \pm$ $0.5 \mathrm{dBZ} \mathrm{km} \mathrm{km}^{-1}$ and slightly negative to neutral slopes for the land regions $(-1-0) \pm 0.5 \mathrm{dBZ} \mathrm{km}^{-1}$ (Hirose and Nakamura 2004; Liu and Zipser 2013). As discussed in section 1, land areas may experience updrafts larger than typical raindrop terminal velocity, creating a situation where the raindrops grow while rising rather than falling. Oceanic regions experience updrafts weaker than terminal fall speed, so raindrops grow while falling to the ground.

We further hypothesize that the magnitude and temperature level (i.e., height) of the mean convective positive slope peaks in Fig. 7c are a direct measure for convective intensity and typical updraft strengths. Taking the mean cold rain stratiform profile as a reference for the extreme case of weak convection, the stronger the slope peak value and the lower the height at which it resides, the weaker the convection. In stratiform rain the reflectivity slope peak is attributed to phase transition from ice to liquid hydrometeors (Fabry and Zawadzki 1995; Wexler 1955). By analogy, we can assume that the slope peak height can be considered as a measure for the effective melting level (transition from ice-phase-dominated hydrometeors to liquid-phasedominated hydrometeors) in the convective cores of these deep clouds.

This hypothesis is tested in Fig. 9. The stratiform slope peaks are all located between the $1^{\circ}$ and $2.5^{\circ} \mathrm{C}$ levels,

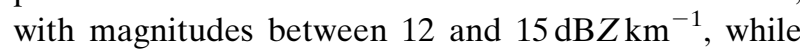
the convective slope peaks are of weaker magnitudes located higher in the atmosphere. Oceanic regions show more "stratiform like" profiles, with larger slope peaks $\left(\sim 6 \mathrm{dBZ} \mathrm{km}{ }^{-1}\right)$ around $0^{\circ} \mathrm{C}$, while land regions (continental and islands) have smaller slope peaks $\left(\sim 4 \mathrm{dBZ} \mathrm{km}^{-1}\right)$ and can reach much higher altitudes (up to the $-7.5^{\circ} \mathrm{C}$ height for Africa-West). Indications for extreme convection for the Africa-West and AfricaEast regions have been previously reported (Boccippio et al. 2000; C. Liu et al. 2012) and are also implied by Table 1, with the former showing the highest LCL height and CAPE and the latter showing the highest mean elevation.

In general, smaller slope peaks coincide with higher peak locations and increased high RTH statistics. These changes can all be explained by the following possible effects of updraft strength on convective cores:

1) Temperature increase in the convective core can raise the $0^{\circ} \mathrm{C}$ isotherm height locally, as temperature excess (of up to $8^{\circ} \mathrm{C}$ ) in convective cores has been shown to coincide with updraft strength (Sinkevich and Lawson 2005). Thus, the effective in-cloud melting layer can reside above the environmental melting layer.

2) Transport of liquid (ice) hydrometeors above (below) the in-cloud melting level can smooth BB layer effects, thus reducing the slope peak near the melting level.

3) Updraft increase should directly increase cloud vertical development and therefore also the RTH.

\section{Summary}

In this work we analyze over 16 years of TRMM reflectivity profiles over several continental and oceanic tropical regions. We find that when data are averaged according to rain top height (RTH), a consistent behavior emerges, where mean reflectivity profiles form non-overlapping manifolds in the heightreflectivity space. Binning by RTH enables one to 


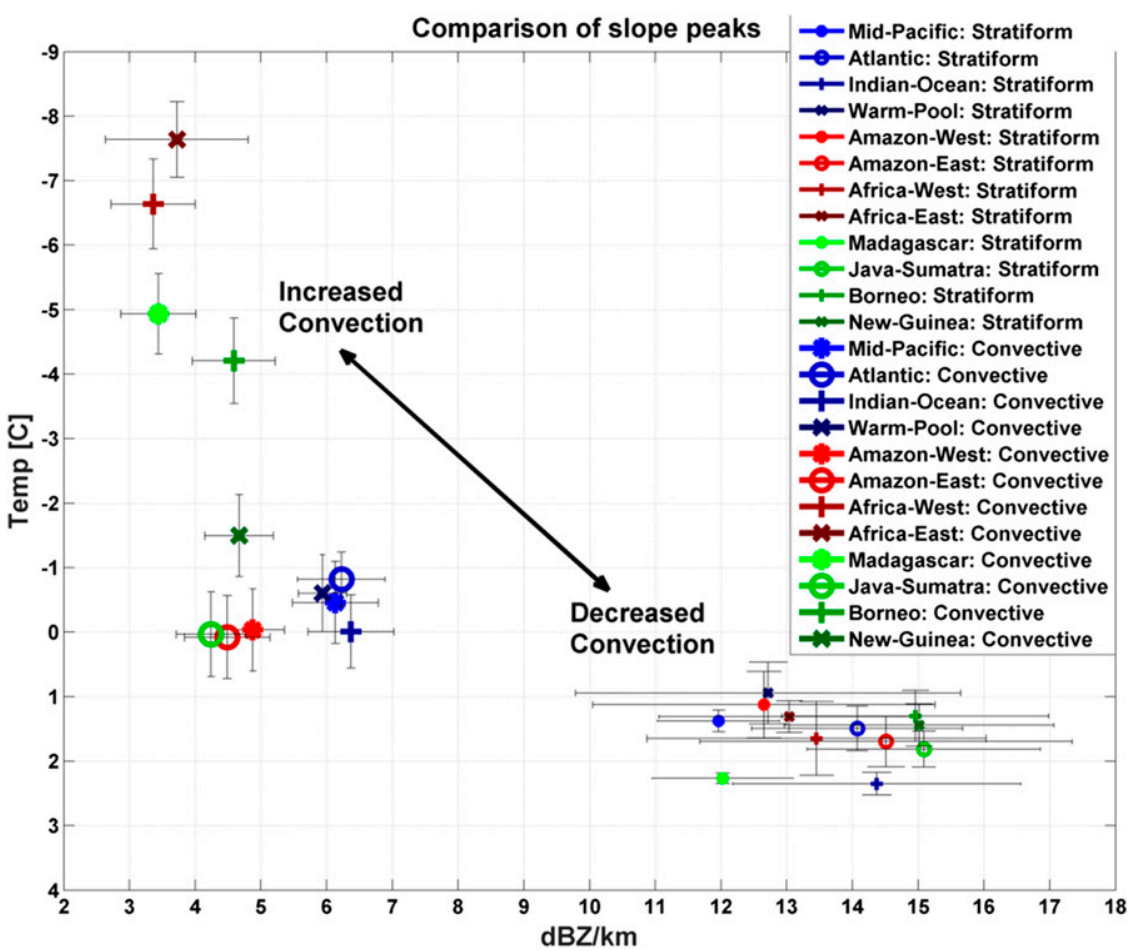

FIG. 9. Reflectivity slope peak magnitude $\left(\mathrm{dBZ} \mathrm{km}{ }^{-1}\right)$ and temperature $\left({ }^{\circ} \mathrm{C}\right)$ for the corresponding profiles shown in Fig. 7. Stratiform (convective) peaks are marked by small (large) markers. Different colors and marker types indicate different regions (see legend). Error bars indicate the std devs around the mean.

link the reflectivity profile characteristics to the dominant hydrometeor growth microphysical processes, which are strongly temperature dependent. Moreover, it is equivalent to binning by local meteorological conditions, since the local thermodynamic conditions are the main factor that determines the cloud development (i.e., RTH is end result of meteorology). This fact, together with similar average thermodynamic conditions in the tropics, enables us to compare results from different regions without additional decoupling of meteorological effects.

In addition to separating the profiles to stratiform and convective rain types, we further divided these types to cold, mixed, and warm rain types according to the top temperature of the profiles (see Table 2 for exact definitions). These divisions were performed based both on physical considerations and empirical interpretations of reflectivity slope profiles. Generally, each of the types above represents a subset of data that shows a consistent profile behavior (cold and warm) or transition between one behavior and another (mixed).

The main finding of this work is that, knowing the $\mathrm{RTH}$ and the type of rain (stratiform or convective) allows for an approximation of the entire averaged vertical reflectivity profile. We find that per rain type, profiles follow similar hydrometeor growth pathways but differ in top heights, which give the average hydrometeor more time to grow. In particular, we note the following findings:

1) Cold rain reflectivity slope profiles are nearly independent of the RTH (i.e., profiles initiated at different RTHs converge to a similar reflectivity slope profile). Warm rain reflectivity slope profiles are strongly dependent on RTH, but show consistent behavior of decreasing reflectivity slope with decreasing height. Mixed rain shows a transition between cold rain and warm rain reflectivity slope profile patterns. These findings are true for both stratiform and convective types.

2) A common reflectivity slope profile was found for stratiform cold rain in all regions (ocean, continental, and islands), despite significant differences in their corresponding convective profiles. This slope profile can be approximated by analytical means [Eq. (2)], depending only on the temperature profile, which is very similar throughout the tropics. It is important to note that this rain type is the most abundant for tropical ITCZ regions. 
3) Interregional differences are most apparent when comparing convective cold rain profiles, where the deviation from the typical stratiform cold rain profile can be used as a measure for convective intensity. Oceanic regions show more similarity with stratiform type profiles, while land regions show smaller reflectivity slope peaks that are also located at higher altitudes, indicative of a higher and smoother effective melting layer (i.e., transition layer of ice-phase-dominated to liquid-phase-dominated hydrometeor regions in the clouds) due to increased updrafts in those regions.

The interregional consistency of reflectivity profiles indicate robustness of the results and imply that dominant microphysical effects in hydrometeor growth can be extracted from these analyses. Measurements and models have shown that the RTH is located only slightly below the cloud-top height (Göke et al. 2007; Khain et al. 2013). Thus, the more easily measured cloud-top height or cloud-top temperature can be used to approximate $\mathrm{RTH}$, which then determines the average vertical profile below. However, we note that the findings here are inherently limited by the sensitivity of TRMM PR ( $\sim 17 \mathrm{~dB} Z)$, as the measurements may be biased to lower rain top heights and higher average reflectivity values. This limitation should be taken into account when comparing with other instruments or applying the data in physical models.

The results in this work raise a conclusion that can be considered analogous in a way to the Marshall-Palmer (MP) distribution of raindrops (Marshall and Palmer 1948). There, only when sufficient statistics of raindrop sizes are taken does the exponential MP distribution appear. Similarly here, only when sufficient statistics (100-10000 counts) of reflectivity profiles are averaged together do we see smooth and consistent behavior of the average reflectivity profile. These average profiles can be used for validation of the calculated profiles by GCMs and could potentially replace the need for computational, costly explicit microphysical schemes when large statistics are considered.

We note that the results in this work only apply to tropical ITCZ regions that all show similar meteorological conditions. Other climatic regions (e.g., semiarid) or weather systems (e.g., extratropical cyclones) may exhibit different behaviors of the average reflectivity profiles. Such comparisons can be put to test in the near future as reflectivity profile data from the GPM satellite are collected, permitting coverage of mid- and high-latitude regions as well.

Acknowledgments. The research leading to these results received funding from the European Research
Council (ERC) under the European Union's Seventh Framework Programme (FP7/2007-13)/ERC Grant Agreement 306965 [Clouds and Precipitation Response to Anthropogenic Changes in the Natural Environment (CAPRI) project] and by NSF Award AGS-1119164. GDAS reanalysis data were obtained from https:// ladsweb.nascom.nasa.gov/search/. TRMM 2A25 data were obtained from ftp://disc2.nascom.nasa.gov/data/ s4pa/TRMM_L2/TRMM_2A25/. TRMM 3B43 data were obtained from ftp://disc2.nascom.nasa.gov/data/ s4pa/TRMM_L3/TRMM_3B43/.

\section{APPENDIX}

\section{Vertical Growth of an Average Hydrometeor}

Here we set the stage for a simplified framework for

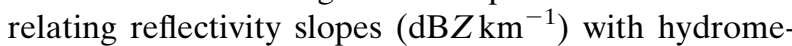
teor growth processes. Our basic assumption is that the reflectivity profile represents a distribution of hydrometeors, generally falling vertically and at the same time growing by various microphysical processes. Reflectivity (i.e., $Z ; \mathrm{mm}^{6} \mathrm{~m}^{-3}$ ) is defined as

$$
Z=\int n(D) D^{6} \partial D
$$

where $D(\mathrm{~mm})$ is the hydrometeor diameter (assuming sphericity) and $n(D)\left(\mathrm{m}^{-3} \mathrm{~mm}^{-1}\right)$ is the hydrometeor size distribution per unit volume. Assuming an MP distribution for the population of hydrometeors [i.e., $n(D)=N_{0} \exp (-D / \bar{D})$, with $\bar{D}$ being the average hydrometeor size], Eq. (A1) can be solved to get

$$
Z=\Gamma(7) N_{0} \bar{D}^{7},
$$

where $N_{0}$ is a constant of order $10^{3}$ and $\Gamma$ is the Gamma function. Using the logarithmic definition of reflectivity $\left[\mathrm{dB} Z=10 \log _{10}\left(Z / 1 \mathrm{~mm}^{6} \mathrm{~m}^{-3}\right)\right]$ one yields to the following expression for reflectivity slopes:

$$
\frac{10 \partial\left(\log _{10} Z\right)}{\partial H} \equiv f(H)=\frac{70}{\ln (10)} \frac{1}{\bar{D}} \frac{\partial \bar{D}}{\partial H},
$$

where $f(H)$ is an arbitrary function dependent on vertical height in the atmosphere, where increasing $H$ represents hydrometeor decrease in height. Integrating Eq. (A3), we get

$$
\bar{D}=\bar{D}_{0} \exp \left[c \int f(H) \partial H\right],
$$

where $c=\ln (10) / 70$ and $\bar{D}_{0}$ is the initial average hydrometeor size (e.g., TRMM detection limit size). 
Hence, it can be seen for an MP distribution of hydrometeors that the growth factor is scaled to the initial hydrometeor size. We note that this fact is inherent to the definition of $\mathrm{dB} Z$ (logarithm of linear reflectivity) and should hold for all types of hydrometeor size distributions (e.g., gamma, lognormal).

\section{REFERENCES}

Andrieu, H., and J. D. Creutin, 1995: Identification of vertical profiles of radar reflectivity for hydrological applications using an inverse method. Part I: Formulation. J. Appl. Meteor., 34, 225-239, doi:10.1175/1520-0450(1995)034<0225: IOVPOR $>2.0 . \mathrm{CO} ; 2$.

Arai, K., and X. Liang, 2010: A comparative study between Mie and Rayleigh scattering assumption based estimation of $Z-R$ relation and rainfall rate with TRMM/PR data. J. Japan Soc. Photogramm. Remote Sens., 49, 67-74, doi:10.4287/jsprs.49.67.

Awaka, J., Y. Furuhama, M. Hoshiyama, and A. Nishitsuji, 1985: Model calculations of scattering properties of spherical brightband particles made of composite dielectrics. J. Radio Res. Lab., 32, 73-87.

_ - T. Iguchi, H. Kumagai, and K. Okamoto, 1997: Rain type classification algorithm for TRMM Precipitation Radar. Proc. IEEE 1997 Int. Geoscience and Remote Sensing Symp., Singapore, Japan, Institute of Electrical and Electronics Engineers, 1633-1635, doi:10.1109/IGARSS.1997.608993.

__, _ , and K. Okamoto, 2009: TRMM PR standard algorithm $2 \mathrm{~A} 23$ and its performance on bright band detection. J. Meteor Soc. Japan, Ser. II, 87A, 31-52, doi:10.2151/jmsj.87A.31.

Berry, E. X., 1967: Cloud droplet growth by collection. J. Atmos. Sci., 24, 688-701, doi:10.1175/1520-0469(1967)024<0688 $\mathrm{CDGBC}>2.0 . \mathrm{CO} ; 2$.

Boccippio, D. J., S. J. Goodman, and S. Heckman, 2000: Regional differences in tropical lightning distributions. J. Appl. Meteor., 39, 2231-2248, doi:10.1175/1520-0450(2001)040<2231: RDITLD $>2.0 . \mathrm{CO} ; 2$.

Bolen, S. M., and V. Chandrasekar, 2000: Quantitative cross validation of space-based and ground-based radar observations. J. Appl. Meteor., 39, 2071-2079, doi:10.1175/1520-0450(2001)040<2071: QCVOSB $>2.0 . \mathrm{CO} ; 2$.

Bolton, D., 1980: The computation of equivalent potential temperature. Mon. Wea. Rev., 108, 1046-1053, doi:10.1175/ 1520-0493(1980)108<1046:TCOEPT > 2.0.CO;2.

Bowen, E. G., 1950: The formation of rain by coalescence. Aust. J. Chem., 3, 193-213, doi:10.1071/CH9500193.

Coumou, D., and S. Rahmstorf, 2012: A decade of weather extremes. Nat. Climate Change, 2, 491-496, doi:10.1038/ nclimate1452.

Craven, J. P., R. E. Jewell, and H. E. Brooks, 2002: Comparison between observed convective cloud-base heights and lifting condensation level for two different lifted parcels. Wea. Forecasting, 17, 885-890, doi:10.1175/1520-0434(2002)017<0885: $\mathrm{CBOCCB}>2.0 . \mathrm{CO} ; 2$.

Donaldson, R. J. J., 1961: Radar reflectivity profiles in thunderstorms. J. Meteor., 18, 292-305, doi:10.1175/1520-0469(1961)018<0292: RRPIT > 2.0.CO;2.

Donner, L. J., and Coauthors, 2011: The dynamical core, physical parameterizations, and basic simulation characteristics of the atmospheric component AM3 of the GFDL Global Coupled Model CM3. J. Climate, 24, 3484-3519, doi:10.1175/ 2011JCLI3955.1.
Fabry, F., and I. Zawadzki, 1995: Long-term radar observations of the melting layer of precipitation and their interpretation. J. Atmos. Sci., 52, 838-851, doi:10.1175/1520-0469(1995)052<0838: LTROOT $>2.0 . \mathrm{CO} ; 2$.

Furuzawa, A. F., and K. Nakamura, 2005: Differences of rainfall estimates over land by Tropical Rainfall Measuring Mission (TRMM) Precipitation Radar (PR) and TRMM Microwave Imager (TMI)-Dependence on storm height. J. Appl. Meteor., 44, 367-383, doi:10.1175/JAM-2200.1.

Göke, S., H. T. Ochs, and R. M. Rauber, 2007: Radar analysis of precipitation initiation in maritime versus continental clouds near the Florida coast: Inferences concerning the role of CCN and giant nuclei. J. Atmos. Sci., 64, 3695-3707, doi:10.1175/ JAS3961.1.

Gunn, K. L. S., and T. W. R. East, 1954: The microwave properties of precipitation particles. Quart. J. Roy. Meteor. Soc., 80, 522545, doi:10.1002/qj.49708034603.

Harper, W. G., 1957: Variation with height of rainfall below the melting level. Quart. J. Roy. Meteor. Soc., 83, 368-371, doi:10.1002/qj.49708335712.

Held, I. M., and B. J. Soden, 2006: Robust responses of the hydrological cycle to global warming. J. Climate, 19, 5686-5699, doi:10.1175/JCLI3990.1.

Heymsfield, G. M., B. Geerts, and L. Tian, 2000: TRMM Precipitation Radar reflectivity profiles as compared with high-resolution airborne and ground-based radar measurements. J. Appl. Meteor., 39, 2080-2102, doi:10.1175/ 1520-0450(2001)040<2080:TPRRPA > 2.0.CO;2.

Hirose, M., and K. Nakamura, 2004: Spatiotemporal variation of the vertical gradient of rainfall rate observed by the TRMM Precipitation Radar. J. Climate, 17, 3378-3397, doi:10.1175/ 1520-0442(2004)017<3378:SVOTVG>2.0.CO;2.

, S. Shimizu, R. Oki, T. Iguchi, D. A. Short, and K. Nakamura, 2012: Incidence-angle dependency of TRMM PR rain estimates. J. Atmos. Oceanic Technol., 29, 192-206, doi:10.1175/ JTECH-D-11-00067.1.

Hosler, C. L., D. C. Jensen, and L. Goldshlak, 1957: On the aggregation of ice crystals to form snow. J. Meteor., 14, 415-420, doi:10.1175/1520-0469(1957)014<0415:OTAOIC>2.0.CO;2.

Hou, A. Y., and Coauthors, 2014: The Global Precipitation Measurement Mission. Bull. Amer. Meteor. Soc., 95, 701-722, doi:10.1175/BAMS-D-13-00164.1.

Houghton, H. G., 1968: On precipitation mechanisms and their artificial modification. J. Appl. Meteor., 7, 851-859, doi:10.1175/1520-0450(1968)007<0851:OPMATA > 2.0.CO;2.

Houze, R. A., 1997: Stratiform precipitation in regions of convection: A meteorological paradox? Bull. Amer. Meteor. Soc., 78, 2179-2196, doi:10.1175/1520-0477(1997)078<2179: SPIROC $>2.0 . \mathrm{CO} ; 2$.

Huffman, G. J., and D. T. Bolvin, 2014: TRMM and other data precipitation data set documentation. NASA TRMM Doc., 42 pp. [Available online at ftp://precip.gsfc.nasa.gov/pub/ trmmdocs/3B42_3B43_doc.pdf.]

Iguchi, T., T. Kozu, R. Meneghini, J. Awaka, and K. Okamoto, 2000: Rain-profiling algorithm for the TRMM Precipitation Radar. J. Appl. Meteor., 39, 2038-2052, doi:10.1175/ 1520-0450(2001)040<2038:RPAFTT >2.0.CO;2.

, — - J. Kwiatkowski, R. Meneghini, J. Awaka, and K. Okamoto, 2009: Uncertainties in the rain profiling algorithm for the TRMM Precipitation Radar. J. Meteor. Soc. Japan, 87A, 1-30, doi:10.2151/jmsj.87A.1.

- S. Seto, R. Meneghini, N. Yoshida, J. Awaka, and T. Kubota, 2010: GPM/DPR level-2. Algorithm Theoretical Basis Doc., 
72 pp. [Available online at https://pmm.nasa.gov/sites/default/ files/document_files/ATBD_GPM_DPR_n3_dec15.pdf.]

Johnson, B. T., G. W. Petty, and G. Skofronick-Jackson, 2012: Microwave properties of ice-phase hydrometeors for radar and radiometers: Sensitivity to model assumptions. J. Appl. Meteor. Climatol., 51, 2152-2171, doi:10.1175/JAMC-D-11-0138.1.

Jorgensen, D. P., and M. A. LeMone, 1989: Vertically velocity characteristics of oceanic convection. J. Atmos. Sci., 46, 621-640, doi:10.1175/1520-0469(1989)046<0621:VVCOOC $>2.0 . C O ; 2$.

Khain, A. P., T. V. Prabha, N. Benmoshe, G. Pandithurai, and M. Ovchinnikov, 2013: The mechanism of first raindrops formation in deep convective clouds. J. Geophys. Res. Atmos., 118, 9123-9140, doi:10.1002/jgrd.50641.

Kirstetter, P.-E., H. Andrieu, B. Boudevillain, and G. Delrieu, 2013a: A physically based identification of vertical profiles of reflectivity from volume scan radar data. J. Appl. Meteor. Climatol., 52, 1645-1663, doi:10.1175/JAMC-D-12-0228.1.

-, Y. Hong, J. J. Gourley, M. Schwaller, W. Petersen, and J. Zhang, 2013b: Comparison of TRMM 2A25 products, version 6 and version 7, with NOAA/NSSL ground radar-based National Mosaic QPE. J. Hydrometeor., 14, 661-669, doi:10.1175/JHM-D-12-030.1.

Kitchen, M., 1997: Towards improved radar estimates of surface precipitation rate at long range. Quart. J. Roy. Meteor. Soc., 123, 145-163, doi:10.1002/qj.49712353706.

Kobayashi, T., 1961: The growth of snow crystals at low supersaturations. Philos. Mag., 6, 1363-1370, doi:10.1080/ 14786436108241231.

Konrad, T. G., 1978: Statistical models of summer rainshowers derived from fine-scale radar observations. J. Appl. Meteor., 17, 171-188, doi:10.1175/1520-0450(1978)017<0171: SMOSRD $>2.0 . \mathrm{CO} ; 2$.

Korolev, A. V., G. A. Isaac, S. G. Cober, J. W. Strapp, and J. Hallett, 2003: Microphysical characterization of mixedphase clouds. Quart. J. Roy. Meteor. Soc., 129, 39-65, doi:10.1256/qj.01.204.

Kostinski, A. B., and R. A. Shaw, 2005: Fluctuations and luck in droplet growth by coalescence. Bull. Amer. Meteor. Soc., 86, 235-244, doi:10.1175/BAMS-86-2-235.

Kozu, T., T. Kawanishi, K. Oshimura, M. Satake, and H. Kumagai, 1994: TRMM Precipitation Radar: Calibration and data collection strategies. IGARSS '94: International Geoscience and Remote Sensing Symposium 1994, Vol. 4, IEEE, 2215-2217, doi:10.1109/IGARSS.1994.399696.

Kummerow, C., W. Barnes, T. Kozu, J. Shiue, and J. Simpson, 1998: The Tropical Rainfall Measuring Mission (TRMM) sensor package. J. Atmos. Oceanic Technol., 15, 809-817, doi:10.1175/ 1520-0426(1998)015<0809:TTRMMT>2.0.CO;2.

Liao, L., and R. Meneghini, 2009: Validation of TRMM Precipitation Radar through comparison of its multiyear measurements with ground-based radar. J. Appl. Meteor. Climatol., 48, 804-817, doi:10.1175/2008JAMC1974.1.

List, R., N. R. Donaldson, and R. E. Stewart, 1987: Temporal evolution of drop spectra to collisional equilibrium in steady and pulsating rain. J. Atmos. Sci., 44, 362-372, doi:10.1175/ 1520-0469(1987)044<0362:TEODST>2.0.CO;2.

Liu, C., and E. J. Zipser, 2013: Why does radar reflectivity tend to increase downward toward the ocean surface, but decrease downward toward the land surface? J. Geophys. Res. Atmos., 118, 135-148, doi:10.1029/2012JD018134.

, D. J. Cecil, E. J. Zipser, K. Kronfeld, and R. Robertson, 2012: Relationships between lightning flash rates and radar reflectivity vertical structures in thunderstorms over the tropics and subtropics. J. Geophys. Res., 117, D06212, doi:10.1029/ 2011JD017123.

Liu, G., 2003: Determination of cloud and precipitation characteristics in the monsoon region using satellite microwave and infrared observations. Mausam, 54, 51-66.

Liu, X.-H., S. Xie, and S. J. Ghan, 2007: Evaluation of a new mixedphase cloud microphysics parameterization with CAM3 single-column model and M-PACE observations. Geophys. Res. Lett., 34, L23712, doi:10.1029/2007GL031446.

Liu, X.-T., Y. Fu, and Q. Liu, 2012: Significant impacts of the TRMM satellite orbit boost on climatological records of tropical precipitation. Chin. Sci. Bull., 57, 4627-4634, doi:10.1007/s11434-012-5357-y.

Ludlam, F. H., 1951: The production of showers by the coalescence of cloud droplets. Quart. J. Roy. Meteor. Soc., 77, 402-417, doi:10.1002/qj.49707733306.

- 1952: The production of showers by the growth of ice particles. Quart. J. Roy. Meteor. Soc., 78, 543-553, doi:10.1002/ qj. 49707833805 .

Marshall, J. S., and W. M. K. Palmer, 1948: The distribution of raindrops with size. J. Meteor., 5, 165-166, doi:10.1175/ 1520-0469(1948)005<0165:TDORWS > 2.0.CO;2.

Marvel, K., and C. Bonfils, 2013: Identifying external influences on global precipitation. Proc. Natl. Acad. Sci. USA, 110, 1930119306, doi:10.1073/pnas.1314382110.

Meerkötter, R., and L. Bugliaro, 2009: Diurnal evolution of cloud base heights in convective cloud fields from MSG/SEVIRI data. Atmos. Chem. Phys., 9, 1767-1778, doi:10.5194/ acp-9-1767-2009.

Meneghini, R., J. Jones, T. Iguchi, K. Okamoto, and J. Kwiatkowski, 2004: A hybrid surface reference technique and its application to the TRMM Precipitation Radar. J. Atmos. Oceanic Technol., 21, 1645-1658, doi:10.1175/ JTECH1664.1.

Mitchell, D. L., 1988: Evolution of snow-size spectra in cyclonic storms. Part I: Snow growth by vapor deposition and aggregation. J. Atmos. Sci., 45, 3431-3451, doi:10.1175/ 1520-0469(1988)045<3431:EOSSSI > 2.0.CO;2.

Mossop, S. C., and J. Hallett, 1974: Ice crystal concentration in cumulus clouds: Influence of the drop spectrum. Science, $\mathbf{1 8 6}$, 632-634, doi:10.1126/science.186.4164.632.

Parrish, D. F., and J. C. Derber, 1992: The National Meteorological Center's spectral statistical-interpolation analysis system. Mon. Wea. Rev., 120, 1747-1763, doi:10.1175/ 1520-0493(1992)120<1747:TNMCSS > 2.0.CO;2.

Petty, G. W., and K. Li, 2013: Improved passive microwave retrievals of rain rate over land and ocean. Part II: Validation and intercomparison. J. Atmos. Oceanic Technol., 30, 25092526, doi:10.1175/JTECH-D-12-00184.1.

Probert-Jones, J. R., 1962: The radar equation in meteorology. Quart. J. Roy. Meteor. Soc., 88, 485-495, doi:10.1002/ qj. 49708837810 .

Pruppacher, H. R., 1995: A new look at homogeneous ice nucleation in supercooled water drops. J. Atmos. Sci., 52, 1924-1933, doi:10.1175/1520-0469(1995)052<1924:ANLAHI > 2.0.CO;2.

_ _ and J. D. Klett, 1978: Microstructure of atmospheric clouds and precipitation. Microphysics of Clouds and Precipitation, Springer, 9-55.

Rakovec, J., 1997: Vertical radar reflectivity profiles in Slovenia. Theor. Appl. Climatol., 57, 35-47, doi:10.1007/BF00867975.

Rosenfeld, D., 2000: Suppression of rain and snow by urban and industrial air pollution. Science, 287, 1793-1796, doi:10.1126/ science.287.5459.1793. 
— , and I. M. Lensky, 1998: Satellite-based insights into precipitation formation processes in continental and maritime convective clouds. Bull. Amer. Meteor. Soc., 79, 2457-2476, doi:10.1175/1520-0477(1998)079<2457:SBIIPF $>2.0 . C O ; 2$.

— tained supercooled liquid water down to $-37.5^{\circ} \mathrm{C}$. Nature, $\mathbf{4 0 5}$, 440-442, doi:10.1038/35013030.

Saha, S., and Coauthors, 2006: The NCEP Climate Forecast System. J. Climate, 19, 3483-3517, doi:10.1175/JCLI3812.1.

Schumacher, C., and R. A. Houze, 2003: The TRMM Precipitation Radar's view of shallow, isolated rain. J. Appl. Meteor., 42, 15191524, doi:10.1175/1520-0450(2003)042<1519:TTPRVO>2.0.CO;2.

$\longrightarrow$, and - 2006: Stratiform precipitation production over subSaharan Africa and the tropical East Atlantic as observed by TRMM. Quart. J. Roy. Meteor. Soc., 132, 2235-2255, doi:10.1256/qj.05.121.

Seifert, A., A. P. Khain, U. Blahak, and K. D. Beheng, 2005: Possible effects of collisional breakup on mixed-phase deep convection simulated by a spectral (bin) cloud model. J. Atmos. Sci., 62, 1917-1931, doi:10.1175/JAS3432.1.

Shige, S., Y. N. Takayabu, W. K. Tao, and D. E. Johnson, 2004: Spectral retrieval of latent heating profiles from TRMM PR data. Part I: Development of a model-based algorithm. J. Appl. Meteor., 43, 1095-1113, doi:10.1175/1520-0450(2004)043<1095: SROLHP $>2.0 . C O ; 2$.

— - S. Kida, H. Ashiwake, T. Kubota, and K. Aonashi, 2013: Improvement of TMI rain retrievals in mountainous areas. J. Appl. Meteor. Climatol., 52, 242-254, doi:10.1175/ JAMC-D-12-074.1.

Sinkevich, A. A., and R. P. Lawson, 2005: A survey of temperature measurements in convective clouds. J. Appl. Meteor., 44, 1133-1145, doi:10.1175/JAM2247.1.

Smull, B. F., and R. A. Houze, 1985: A midlatitude squall line with a trailing region of stratiform rain: Radar and satellite observations. Mon. Wea. Rev., 113, 117-133, doi:10.1175/ 1520-0493(1985)113<0117:AMSLWA > 2.0.CO;2.

Snyder, J. C., A. V. Ryzhkov, M. R. Kumjian, A. P. Khain, and J. Picca, 2015: A $Z_{\mathrm{DR}}$ column detection algorithm to examine convective storm updrafts. Wea. Forecasting, 30, 1819-1844, doi:10.1175/WAF-D-15-0068.1.

Stith, J. L., J. E. Dye, A. Bansemer, A. J. Heymsfield, C. A. Grainger, W. A. Petersen, and R. Cifelli, 2002: Microphysical observations of tropical clouds. J. Appl. Meteor., 41, 97-117, doi:10.1175/1520-0450(2002)041<0097:MOOTC $>2.0 . C O ; 2$.

Sui, C.-H., and X. Li, 2005: A tendency of cloud ratio associated with the development of tropical water and ice clouds. Terr. Atmos. Ocean. Sci., 16, 419-434.

Szoke, E. J., E. J. Zipser, and D. P. Jorgensen, 1986: A radar study of convective cells in mesoscale systems in GATE. Part I: Vertical profile statistics and comparison with hurricanes. J. Atmos. Sci., 43, 182-198, doi:10.1175/1520-0469(1986)043<0182: ARSOCC $>2.0 . \mathrm{CO} ; 2$.

Takayabu, Y. N., 2002: Spectral representation of rain profiles and diurnal variations observed with TRMM PR over the equatorial area. Geophys. Res. Lett., 29, 1584, doi:10.1029/2001GL014113.

Trenberth, K. E., J. T. Fasullo, and J. Kiehl, 2009: Earth's global energy budget. Bull. Amer. Meteor. Soc., 90, 311-323, doi:10.1175/2008BAMS2634.1.

Uijlenhoet, R., 2001: Raindrop size distributions and radar reflectivity-rain rate relationships for radar hydrology. $H y$ drol. Earth Syst. Sci., 5, 615-627, doi:10.5194/hess-5-615-2001.

_ J. A. Smith, and M. Steiner, 2003: The microphysical structure of extreme precipitation as inferred from ground-based raindrop spectra. J. Atmos. Sci., 60, 1220-1238, doi:10.1175/ 1520-0469(2003)60<1220:TMSOEP >2.0.CO;2.

Vignal, B., H. Andrieu, and J. D. Creutin, 1999: Identification of vertical profiles of reflectivity from volume scan radar data. J. Appl. Meteor., 38, 1214-1228, doi:10.1175/1520-0450(1999)038<1214: IOVPOR $>2.0 . \mathrm{CO} ; 2$.

Viltard, N., C. Burlaud, and C. D. Kummerow, 2006: Rain retrieval from TMI brightness temperature measurements using a TRMM PR-based database. J. Appl. Meteor. Climatol., 45, 455-466, doi:10.1175/JAM2346.1.

Waliser, D. E., and C. Gautier, 1993: A satellite-derived climatology of the ITCZ. J. Climate, 6, 2162-2174, doi:10.1175/ 1520-0442(1993)006<2162:ASDCOT $>2.0 . C O ; 2$.

Wang, J., and D. B. Wolff, 2009: Comparisons of reflectivities from the TRMM Precipitation Radar and ground-based radars. J. Atmos. Oceanic Technol., 26, 857-875, doi:10.1175/ 2008JTECHA1175.1.

— ground measurements over central Florida. J. Appl. Meteor. Climatol., 51, 926-940, doi:10.1175/JAMC-D-11-080.1.

Wexler, R., 1955: An evaluation of the physical effects in the melting layer. Preprints, Fifth Weather Radar Conf., Fort Monmouth, NJ, Amer. Meteor. Soc., 329-334.

Williams, E., and S. Stanfill, 2002: The physical origin of the landocean contrast in lightning activity. C. R. Phys., 3, 1277-1292, doi:10.1016/S1631-0705(02)01407-X.

-, and Coauthors, 2002: Contrasting convective regimes over the Amazon: Implications for cloud electrification. J. Geophys. Res., 107, 8082, doi:10.1029/2001JD000380.

Willis, P. T., and A. J. Heymsfield, 1989: Structure of the melting layer in mesoscale convective system stratiform precipitation. J. Atmos. Sci., 46, 2008-2025, doi:10.1175/ 1520-0469(1989)046<2008:SOTMLI>2.0.CO;2.

Wilson, J. W., and E. A. Brandes, 1979: Radar measurement of rainfall-A summary. Bull. Amer. Meteor. Soc., 60, 1048-1058, doi:10.1175/1520-0477(1979)060<1048:RMORS > 2.0.CO;2.

Xue, Y., L.-P. Wang, and W. W. Grabowski, 2008: Growth of cloud droplets by turbulent collision-coalescence. J. Atmos. Sci., 65 , 331-356, doi:10.1175/2007JAS2406.1.

Young, K. C., 1975: The evolution of drop spectra due to condensation, coalescence and breakup. J. Atmos. Sci., 32, 965-973, doi:10.1175/1520-0469(1975)032<0965:TEODSD>2.0.CO;2.

Yuan, T., J. V. Martins, Z. Li, and L. A. Remer, 2010: Estimating glaciation temperature of deep convective clouds with remote sensing data. Geophys. Res. Lett., 37, L07108, doi:10.1029/ 2010 GL042711.

Yuter, S. E., and R. A. Houze, 1995: Three-dimensional kinematic and microphysical evolution of Florida cumulonimbus. Part II: Frequency distributions of vertical velocity, reflectivity, and differential reflectivity. Mon. Wea. Rev., 123, 1941-1963, doi:10.1175/1520-0493(1995)123<1941:TDKAME > 2.0.CO;2.

Zheng, Y., and D. Rosenfeld, 2015: Linear relation between convective cloud base height and updrafts and application to satellite retrievals. Geophys. Res. Lett., 42, 6485-6491, doi:10.1002/2015GL064809.

, — _ and Z. Li, 2015: Satellite inference of thermals and cloud-base updraft speeds based on retrieved surface and cloud-base temperatures. J. Atmos. Sci., 72, 2411-2428, doi:10.1175/JAS-D-14-0283.1.

Zipser, E. J., and K. R. Lutz, 1994: The vertical profile of radar reflectivity of convective cells: A strong indicator of storm intensity and lightning probability? Mon. Wea. Rev., 122, 1751-1759, doi:10.1175/1520-0493(1994)122<1751:TVPORR>2.0.CO;2. 